\title{
THREE-DIMENSIONAL MODELLING OF REINFORCED CONCRETE WITH MULTI-DIRECTIONAL CRACKING
}

\author{
Bernhard HAUKE ${ }^{1}$ and Koichi MAEKAWA ${ }^{2}$ \\ ${ }^{1}$ Member of JSCE, Dipl.-Ing., Ph.D., HOCHTIEF IKS \\ (Bockenheimer Landstr, Frankfurt 60323, Germany) \\ ${ }^{2}$ Member of JSCE, Dr. of Eng., Professor, Dept. of Civil Eng., The University of Tokyo \\ (Hongo 7-3-1, Bunkyo-ku, Tokyo 113-0033, Japan)
}

\begin{abstract}
This paper presents a three-dimensional (3D) constitutive model for non-linear finite element (FE) analysis of reinforced concrete with special attention to cracked concrete. Post-cracking formulations derived from uni-axial tension are generalised to the spatially arbitrarily inclined cracks with multidirection. Anisotropic concrete tension fracture and reinforcement mean yield levels of the spatially averaged RC-model in association with a 3D RC-zoning concept are discussed. The proposed model is verified by numerically simulating inherently $3 \mathrm{D}$ shear failure of $\mathrm{RC}$ members subjected to torsion and RC short columns loaded in multi-directional shear.
\end{abstract}

Key Words: Multi-directional crack, 3D-constitutive law, anisotropic fracture, finite element analysis, zoning, shear failure

\section{INTRODUCTION}

With continuing computer hardware development and with new findings in material research, the finite element method can be used for the simulation of experiments and the prediction of structural safety and serviceability performances of reinforced concrete in general. The world wide research effort of almost three decades led to the development of elaborate constitutive models of reinforced concrete for in-plane structures. At the same time, only a few applications involving full 3D modelling of structural geometry, stress states and loading patterns have emerged in the literature.

In this paper, 3D constitutive models of reinforced concrete with special attention to post cracking formulations are introduced. In 2D-reduced analysis, element-wise quasi-isotropic cracked reinforced concrete formulations may be reasonable to some extent since crack orientation can only be directed in a plane. In a more generic approach of full 3D, however, stress and strain fields are modelled as they are and anisotropy of the spatially averaged RC-model is encountered. This is because any discretionary crack inclination is allowed in the 3D space whilst full bond effect can be only assumed in the direction(s) of reinforcing bar(s). Then, post-cracking response based on the smeared modelling concept, derived from uni-axial tension, is necessary to be extended to the more generic situation of spatially arbitrary crack inclination with respect to reinforcement as may be encountered in reinforced concrete subjected to non-trivial loading.

For verification of the proposed 3D constitutive relations, plain and reinforced concrete members subjected to torsion and short RC columns under multi-lateral loading in shear were selected. The load bearing mechanism becomes inherently threedimensional and the problem can not be solved by 2D analysis in nature. In fact, most reinforced concrete structures are subjected to complex load patterns in their live time. Short columns serving highway bridges, for example, are exposed to axial load and combined uni-axial shear and flexure under serviceability conditions, which is a standard 2D problem. However, in the case of earthquake actions or accidental impact, such columns have to sustain multi-directional shear and/or torsion. Then, it is necessary not only to understand but also numerically simulate the complex behaviours of RC structures under non-proportional multi-lateral loading patterns (See Fig.1). This is to fulfil the demands of the performance based design philosophy of the next generation structural codes requiring engineers to check the specified limit states and guarantee the quality to the public. Here, especially, structures have to be checked for seismic or accidental resistance in reasonable consistency with material and structural mechanics requiring a versatile computational tool for examining structural performances. 


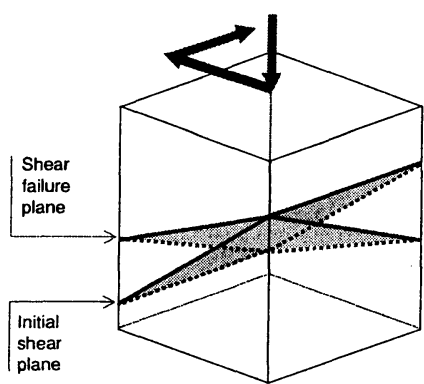

Fig.1 Short RC-column subjected to non-proportional multi-directional loading.

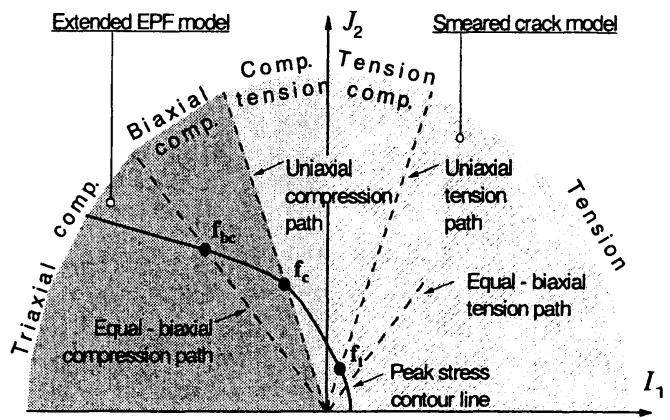

Fig.2 Generic concrete models for complete 3D-stress space $^{3)}$.

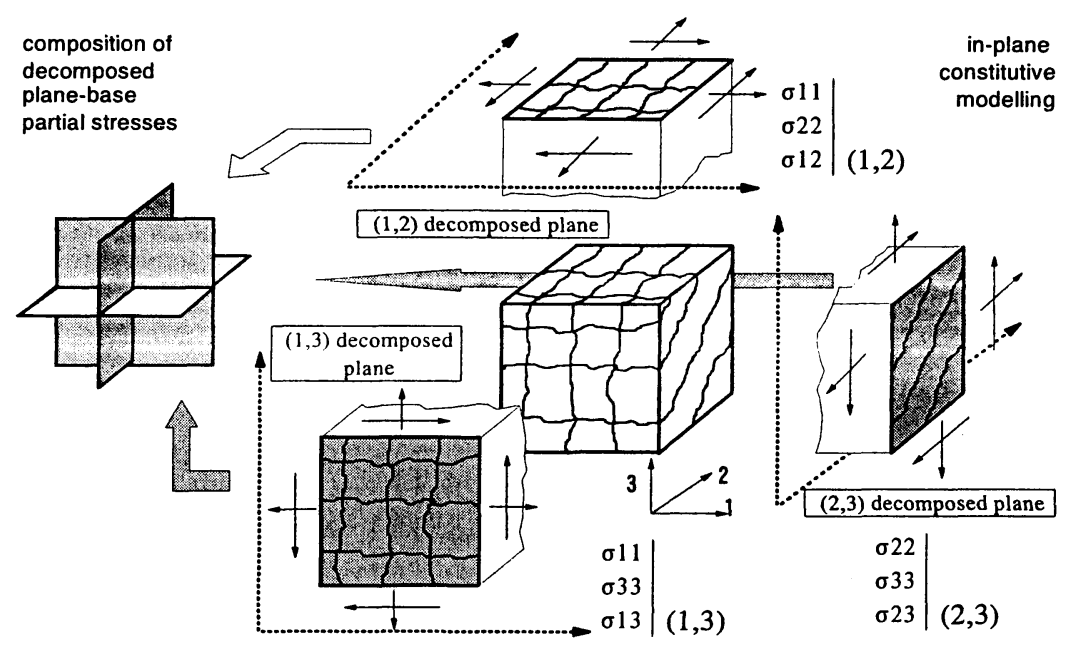

Fig.3 Re-composition of load carrying mechanism of 3D cracked solids of concrete with multi-directional cracking.

\section{RC-BRICK ELEMENT}

\section{(1) General concept}

Reinforced concrete is idealised as a composite material consisting of concrete and reinforcement to be superimposed. By combining the constitutive laws of average stress and average strain for concrete and reinforcement ${ }^{1)}$, respectively, the RC brick element has been constructed. In FE computation, isoparametric brick elements with 20 nodes are used for reinforced concrete. Concrete is, according to its state, treated in an un-cracked or a cracked concrete routine of the structural analysis frame (see Fig.2). The generation of cracks is a branching point into strong anisotropic nonlinearity and at the same time, it marks the switching of concrete model of the proposed analysis concept. Crack initiation is decided by a simple Rankine criterion. Realising that the damage accumulation of concrete in compression and tension prior to cracking is basically of a blunt non-local continuum nature, while post-cracking behaviour can be thought as a highly localised process, the separate treatment of un-cracked and cracked concrete seems to be reasonable. The phenomenon of post-peak compression softening remains un-addressed as outside of the present framework and a challenging topic of further research.

\section{(2) Extended elasto-plastic and continuum fracture model for un-cracked concrete}

In the pre-cracking range, the triaxial elastoplastic and continuum damage/fracturing (EPF) model for concrete ${ }^{2)}$ is employed. Mechanical behaviours of concrete is idealised as combined plasticity and continuum fracture which identifies induced permanent deformations and the loss of elastic energy absorption capacity, respectively. The model, which was originally developed for full triaxial compression, had recently been extended to the whole 3D-space, covering tension domain of pre-cracked concrete ${ }^{3)}$ as shown in Fig.2. 


\section{(3) 3D multi-directional smeared crack model}

The introduction of cracks in concrete marks the transition from an idealised 3D continuum, treated by the EPF-model, toward a highly anisotropic medium. Owing to crack stress release, the 3Dconfinement effect may be assumed to be much reduced for cracked concrete. Noting this inherent breakdown of 3D continuity, smeared crack modelling of three-dimension based on cracked concrete in-plane constitutive law under cyclic forces had been proposed by Maekawa et al. ${ }^{4)}$. After closure of pre-cracking under load reversals, the constitutive model is switched back to the elastoplastic and continuum fracture model of un-cracked concrete, and tri-axial confinement effect on concrete in compression is considered again.

An orthogonal Cartesian co-ordinate system is assumed whose principal axis (1) is normal to the initially introduced crack plane and the remaining axes (2 and 3 ) are placed within the first crack reference plane. Here, we can define tw.odimensional sub-spaces designated by axis $(1,2),(2$, $3)$ and $(1,3)$ as shown in Fig.3. The initial crack would be contained in $(1,2)$ and $(1,3)$ planes, while plane $(2,3)$ coincides with the plane of the initial crack. Any further crack would then be completely treated in the fixed two-dimensional sub-spaces decided based on the initial crack.

Now, the partial stresses rooted in the crack projection on $(i, j)$ can be computed in use of inplane RC constitutive law accompanying multidirectional cracking. Let $\sigma_{\mathrm{ij}}{ }^{(\mathrm{k}, \mathrm{l})}$ denote the reduced component stress computed based on mean strain on $(\mathrm{k}, 1)$ sub-space. When we simply assume the total load carrying mechanism as being composed of partial stresses on three sub-spaces, we have,

$$
\begin{gathered}
\sigma_{i i}=\frac{1}{2} \sum_{k \neq i} \sigma_{i i}^{(i, k)} \quad\left(\left.\varepsilon_{s t}\right|_{s, t=i \vee k}\right) \\
\left.\sigma_{i j}\right|_{i \neq j}=\sigma_{i j}^{(i, j)} \quad\left(\left.\varepsilon_{s t}\right|_{s, t=i \vee k}\right)
\end{gathered}
$$

where, in-plane membrane constitutive equation is used for computing component stress $\sigma_{i j}{ }^{(k, l)}$ from sub-space strains as $\varepsilon_{\mathrm{st}(\mathrm{s}, \mathrm{t} \vee \mathrm{k}, \mathrm{l})}$.

For computation of 2D sub-space component stresses, the newly proposed four-way fixed crack model of Fukuura and Maekawa ${ }^{5)}$ is utilised. The model fictitiously considers up to nine cracks at each integration point in the scheme of 3D smeared crack idealisation. The in-plane smeared crack model is composed of tension stiffening model across cracks, compression stiffening/softening model parallel to cracks and shear transfer model along cracks as described in Okamura and

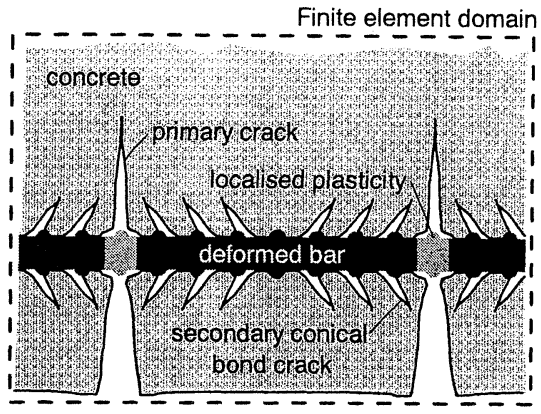

Fig.4 Formation of cracks in finite element domain.

Maekawa ${ }^{1)}$. The scheme of the four-way fixed crack model, management of active and dormant cracks and their verifications are given in the literature by Fukuura and Maekawa ${ }^{5)}$.

\section{(4) Distributed reinforcement}

In the three-dimensional modelling of RCstructures, rather than structural details, modelling of smeared and distributed reinforcing bars in space is thought advantageous, since it does not require any additional nodes or elements as are necessary for discrete or embedded representations. Hence, it simplifies the generation of 3D reinforced concrete meshes. Furthermore, when we would use a discrete reinforcing bar model in concrete, much finer finite elements have to be allocated for numerically simulating localised yielding of reinforcement close to crack planes.

But, the smeared reinforcement model can take into account the localised plasticity in a finite element by spatially averaged constitutive law of steel embedded in concrete with bond interaction. Then, for reinforcement orthogonally arranged in space and distributed representation without dowel shear stiffness had been adopted. In the smeared approach, localisation of initial steel plasticity close to cracks and local bond slip effect are considered in computing the mean stress-strain relation based on the local bond-slip-strain behaviour ${ }^{1)}$.

\section{SPATIALLY ANISOTROPIC POST- CRACING RESPONSE}

\section{(1) Effective embedment (RC) zone}

In $3 \mathrm{D}$ finite element computations of real scale reinforced concrete structures, number of finite elements is limited due to restricted computational capacity. Then, for engineering purpose, larger elements are likely to be employed. Within the volume of the finite element domain, both primary and secondary cracks may develop (Fig.4) whilst concrete in-between still can sustain tensile stresses 
transferred through bond action from the reinforcement. Hence, spatially average stress average strain relations ${ }^{1)}$ representing the mean behaviour of the element volume have been developed and are widely used.

If we could allocate many smaller elements, such that all local cracks as well as un-cracked concrete between primary cracks could be separately captured, no average based concrete and reinforcement models might be necessary. In such a case, of course, no tension stiffening or RC-zoning needs to be considered since contribution of concrete between cracks is intrinsically considered.

However, as mentioned above, such a fine $\mathrm{FE}$ mesh for RC-structures of engineering interest can not be analysed within reasonable time considering the present computer technology. Then, for 3D finite elements with some finite volume, so called zoning concept ${ }^{8)}$ is necessary to correctly detect distinct average constitutive laws of concrete close and far from reinforcement and consider spatial orientations of bond effect on concrete.

As a matter of fact, bond is an inherently 3D problem with the conical shape of secondary cracks (Fig.4) which can not be treated physically consistent in 2D extent. Strictly speaking, any 2D approach $^{6}$, which omits tension stiffening formulations and uses a large numbers of small elements instead is inconsistent. In that case, secondary bond cracks, once generated, can propagate progressively since crack front is just a point. In reality, secondary bond cracks may propagate in a conical shape and circular crack front enlarges as crack ligament develops. Here, cracking cannot be progressive but because of the enlarging crack front, its propagation is eventually stopped.

Tension stiffening model for reinforced concrete, mentioned in the previous section as an essential part of the average based cracked concrete routine, had been derived from uni-axial tension tests ${ }^{7}$. In these tests, tensile strain is nearly uniformly distributed over the section and the reinforcement ratio was above the minimum one. In this case, cracks form only normal to the reinforcement and softening behaviour of the whole concrete volume is controlled by reinforcement. In practical reinforced concrete structures, however, strain gradients and reinforcement ratio below the critical one may be found and cracks may not always form normal to the reinforcing bars. Consequently, concrete close to the reinforcement may, due to the bond effect, stiffen in a similar way as observed in the uni-axial tension tests, while concrete far away from the reinforcement behaves as brittle plain concrete ${ }^{8)}$.

Gupta and Tanabe ${ }^{9)}$ raised the question whether tension stiffening diagrams obtained from uni-axial

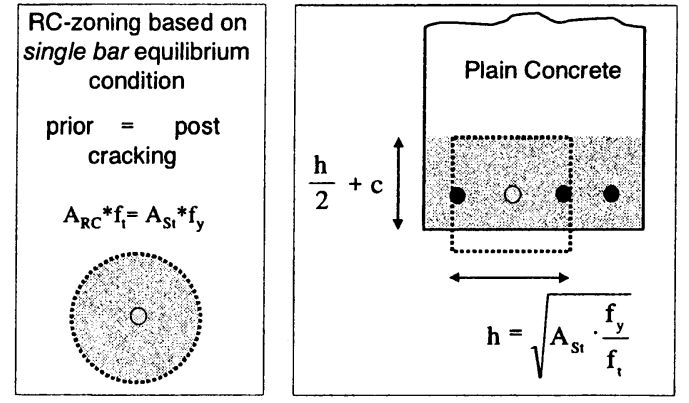

Fig.5 Single bar RC-zoning concept.

tension tests could be applied for a general loading case of RC-structures exhibiting strain gradients. Barzegar and Maddipudi ${ }^{10)}$ presented a solution for this problem by selecting distinct fracture energies for different plain and reinforced concrete structures, which might reflect the average behaviour of the structure. For un-reinforced specimen, specified fracture energy is in the common range of concrete. For reinforced concrete members, on the other hand, isotropic tension stiffening effect is implicitly considered by allocating larger fracture energy values. Then, depending on reinforcement arrangement and expected strain gradient, a kind of fracture energy could be decided, which would be rather a structural than a material property.

However, no information is given how the fracture energy be decided for different RC-structures and whether it can be clearly determined or is just a mere fitting parameter.

From the above discussion, it becomes clear that some sort of more rational method is desired. It would allow us to detect the volume of concrete to which bond reaches, so that softening behaviour is controlled by reinforcement through bond action and must be distinguished from plain concrete because of its evident tension stiffening characteristics. Such a zone might be called effective embedment or RC-zone ${ }^{8)}$. A simple engineering method to determine the RC-zone in $2 \mathrm{D}$ problems based on a single bar equilibrium condition as shown in Fig.5 had been proposed by An et al. ${ }^{8}$. RC-zone for a single reinforcing bar is determined by the condition that the tension force carried by RC-zone concrete just prior to cracking must be equal to the yield force which the reinforcing bar can support at maximum through bond mechanism after cracking, formulated as ${ }^{8)}$,

$$
A_{R C}=\frac{A_{s t} \cdot f_{y}}{f_{t}}
$$

where, $A_{R C}$ is maximum area of bond effect zone in concrete, $A_{s t}$ is area of steel bar, $f_{t}$ is concrete tensile 


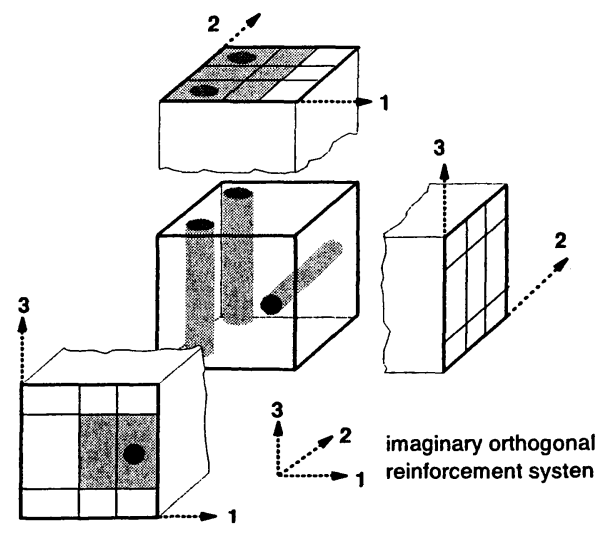

Fig.6 3D RC-zoning concept using an imaginary orthogonal reinforcing system.

strength and $f_{y}$ is yielding strength of steel bar (Fig.5). Or, in other words, the reinforcement ratio of the RC-zone is assumed equal to the critical reinforcement ratio $f_{t} / f_{y}$. Overlapping RC-zones associated with neighbouring reinforcing bars is not additionally accounted for as well as the part of the RC-zone that falls outside the structure boundary as illustrated in Fig.5.

Originally proposed 2D RC-zoning method ${ }^{8)}$ does not account for the directional feature of bond effect on concrete. Finite elements, which are found to be in the effective embedment zone of a reinforcing bar are designated isotropic tension stiffening. For simple arrangement of reinforcement and load pattern chiefly generating cracks perpendicular to that reinforcement, this assumption may lead to good results.

Overcoming this restriction by a more versatile RC-zoning concept, an imaginary three-directional, orthogonal reinforcement system is introduced. In each of the respective directions, $\mathrm{RC}$-zoning method is applied independently. Then, if none of those three directions of a control volume would contain reinforcement, isotropic plain concrete is assumed while all three directions containing reinforcement would mark isotropic reinforced concrete. Any other combination, however, would lead to an anisotropic reinforced/plain concrete behaviour of the respective finite elements in the control volume (Fig.6).

It had been found that for deep structural members, such as beams or columns, the influence of splitting cracks on bond and tension stiffening is negligible, even if the concrete cover is deficient from one side ${ }^{11)}$. This is because of the confinement of the surrounding concrete and possible hoop reinforcement ${ }^{11}$. Then, in this study, no reduction of $\mathrm{RC}$-zone in relation with insufficient concrete cover is considered for simplicity.

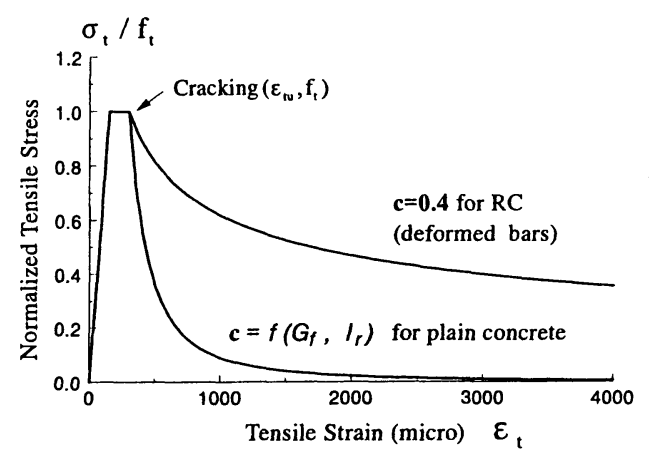

Fig.7 Tension model for plain and reinforced concrete ${ }^{1)}$.
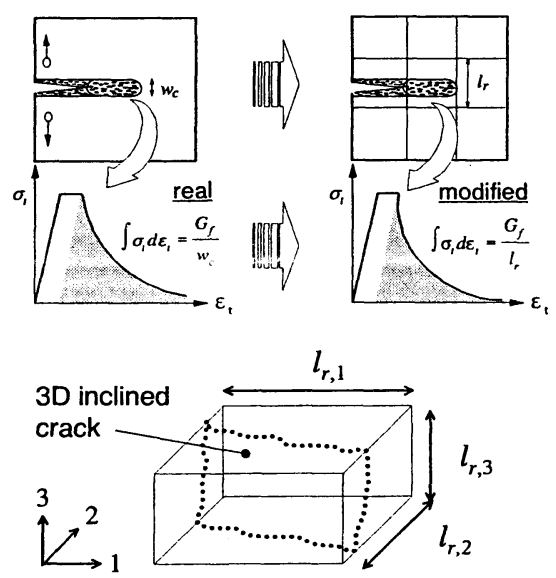

Fig.8 Crack band theory for smeared modelling of concrete tension fracture in 2D and 3D.

\section{(2) Anisotropic tension fracture}

The post cracking concrete tension model was proposed by Okamura and Maekawa ${ }^{1)}$ as,

$$
\sigma_{t}=f_{t}\left(\varepsilon_{t u} / \varepsilon_{t}\right)^{c}
$$

where " $c$ " is the parameter describing the inclination of the descending envelope curve and $\varepsilon_{\mathrm{tu}}$ is the cracking strain (see Fig.7).

For plain concrete softening, in order to avoid spurious mesh dependence, the softening parameter in Eq.(3) has to be defined by means of energy based fracture mechanics requirement ${ }^{8}$. According to the crack band theory ${ }^{12)}$, plain concrete softening can be determined from fracture energy in association with the reference length of smeared crack elements (Fig.8). For the present postcracking tension model, softening parameter denoted by " $c$ " is obtained by satisfying, 


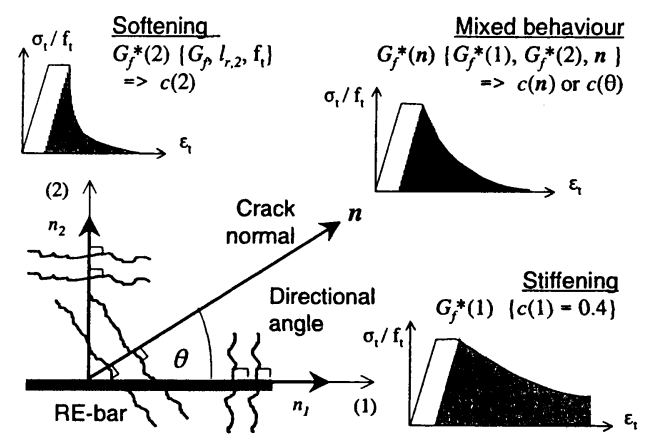

Softening parameter $c(1), c(2)$ according to Re-bar arrangement
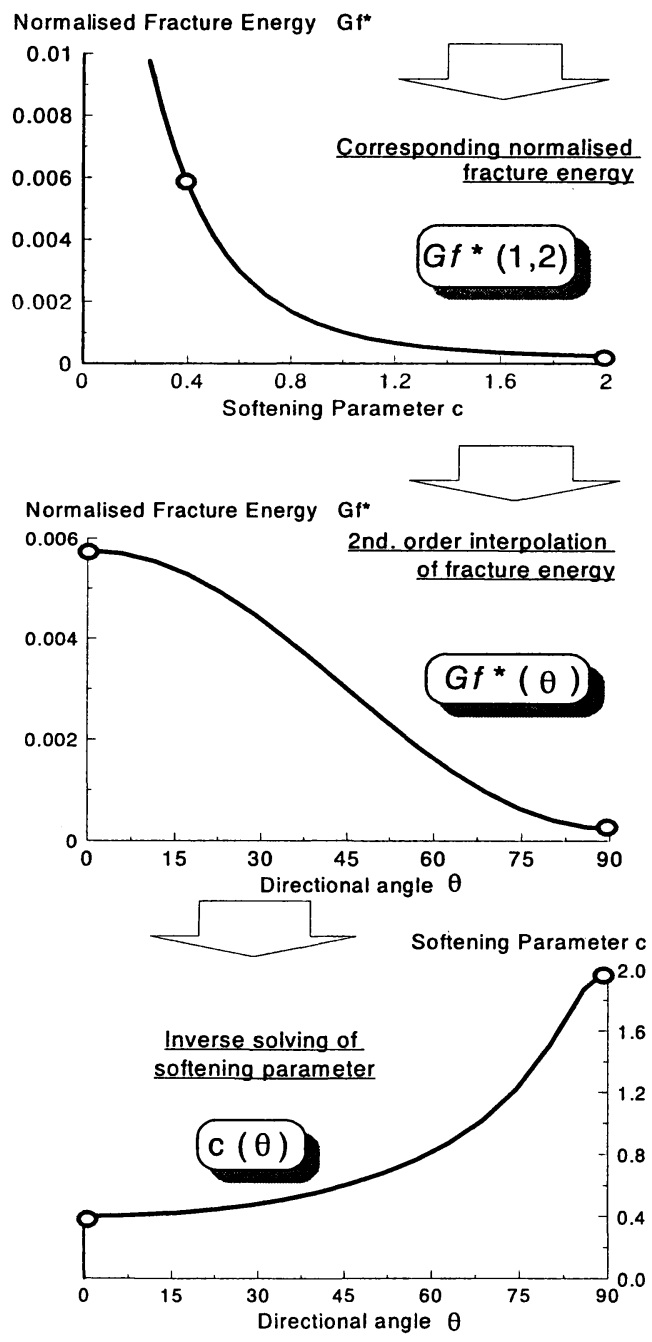

Fig.9 Fracture energy based interpolation scheme of softening parameter for inclined cracks.

$$
\int \sigma_{t} d \varepsilon_{t}=G_{f} / l_{r}
$$

where, $G_{f} ; l_{r}$ are fracture energy of concrete and the reference length on which the average softening stress-strain relation is defined. Simple a priori methods for determining $l_{r}$ using the square root of element area $^{8)}$ or volume are, strictly speaking, restricted to regular meshes with cracks running mostly parallel to the mesh peripheral lines.

However, for the general case of rectangular solid elements with inclined cracks, a more precise estimation seems desirable. In this research, tension softening is decided in each global direction, respectively, by taking the corresponding element dimension as reference length (Fig.8). For cracks not running parallel to one of the element faces, an interpolation scheme based on normalised fracture energy $G_{f}^{*}$ is described in the following section.

Tension stiffness model for reinforced concrete has the same mathematical form as the softening model ${ }^{1)}$. In case of RC, softening factor $\mathrm{c}$ in Eq.(3) was verified constant ( 0.4 for deformed bar) and independent of finite element size provided that the reinforcement ratio of the volume concerned is higher than the critical reinforcement ratio ${ }^{1)}$. With respect to the RC-zoning method previously described, this condition is always fulfilled.

Different softening/stiffening behaviour of plain and reinforced concrete and the conforming zoning method are introduced in general. Now, their interaction in 3D application shall be discussed. Cracks generated in a concrete control volume may have any arbitrary inclination in space. If such a crack is located in the plain concrete zone, the softening behaviour differs with the crack orientation and element geometry. For a control volume containing reinforcement in one or several directions the average softening/stiffening behaviour depends furthermore on the crack inclination relative to the bar. A crack normal to reinforcement will exhibit stiffening due to bond development while the other parallel crack without any intersection with steel would be softening. Consequently, a crack which is neither parallel nor normal to a reinforcing bar but discretionally inclined must show a mixed softening/stiffening behaviour as shown in Fig.9. It might be opportune to call this dependency of reinforced concrete post cracking behaviour on the crack orientation with respect to reinforcement anisotropic softening.

Firstly, applying RC zoning in all three directions of the reinforcement system defines distinct softening and stiffening characteristics in an orthogonal system. For randomly inclined cracks, the softening behaviour must be interpolated. Since the relationship between the softening parameter 
and the fracture energy is highly nonlinear, the parameter " $c$ " can not be decided by mere interpolation. Non-dimensional fracture energy, normalised by tension strength and reference length, can be used instead and is defined as,

$$
G_{f}^{*}=\frac{G_{f}}{\mathrm{f}_{t} l_{r}}=\frac{1}{\mathrm{f}_{t}} \int_{\varepsilon_{t u}}^{\varepsilon_{t e}} \sigma_{t} d \varepsilon_{t}+\frac{1}{4} \varepsilon_{t u}
$$

By substituting Eq.(3) into Eq.(5) and executing the integration, we have,

$$
G_{f}^{*}=\frac{\varepsilon_{t u}}{c-1}\left[1-\left(\frac{\varepsilon_{t e}}{\varepsilon_{t u}}\right)^{1-c}\right]+\frac{1}{4} \varepsilon_{t u}
$$

where, $\varepsilon_{t e}$ denotes ultimate tensile strain used as integration limit. Then, $G_{f}{ }^{*}$ for plain concrete can be computed based on fracture mechanical requirement Eq.(5) and for reinforced concrete based on empirical stiffening parameter in Eq.(6).

Here, the normalised fracture energy defined in the orthogonal system has to be interpolated. As slight deviation of the crack from the bar direction would not cause much reduction of fracture energy, the $2^{\text {nd }}$ order interpolation is proposed as a simple mechanical model. An in-plane simplified situation as illustrated in Fig.9 would lead to,

$$
G_{f}^{*}(n)=\frac{n_{1}^{2} G_{f}^{*}(1)+n_{2}^{2} G_{f}^{*}(2)}{n_{1}^{2}+n_{2}^{2}}
$$

where, $n_{1}$ and $n_{2}$ are the components of the crack normal unit vector $\boldsymbol{n}$. If we introduce the directional angle $\theta$ of the crack normal relative to the reinforcing bar, components are $n_{1}=\cos \theta$ and $n_{2}=$ $\sin \theta$ and hence, we can write the interpolation as,

$$
G_{f}^{*}(\theta)=\cos ^{2} \theta G_{f}^{*}(1)+\sin ^{2} \theta G_{f}^{*}(2)
$$

Having computed $G_{f}^{*}(\theta)$, the softening parameter "c" of the arbitrary angle can be obtained by inversely solving Eq.(6) as shown in Fig.9. The conforming $3 \mathrm{D}$ interpolation is straightforward obtained as,

$$
G_{f}^{*}(n)=\frac{n_{1}^{2} G_{f}^{*}(1)+n_{2}^{2} G_{f}^{*}(2)+n_{3}^{2} G_{f}^{*}(3)}{n_{1}^{2}+n_{2}^{2}+n_{3}^{2}}
$$

Distinct tension softening and stiffening characteristics in full 3D space are defined and the respective information is transferred to the $2 \mathrm{D}$ subspaces ${ }^{4)}$ where the softening parameter is finally utilised in Eq.(3) for post cracking tension analysis ${ }^{1)}$.

\section{(3) Anisotropic shear transfer model}

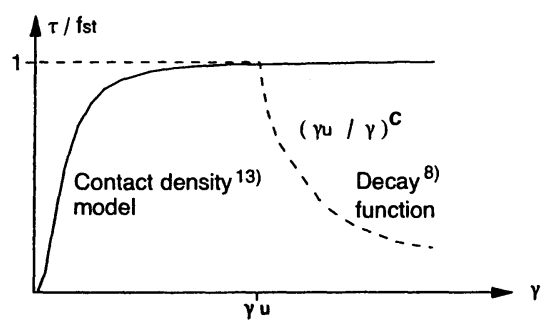

Fig.10 Original shear transfer (contact density) model and decay function.

Since the generation of cracks in concrete is decided by the maximum principal stress criterion, at the moment of cracking, shear stress and strains are zero on the crack plane normal to the maximum principal stress direction. However, as loading proceeds, principal axes of stress and strain rotate which eventually leads to the introduction of a new crack. At the same time, the existing crack is subjected to shear strain since the crack is no longer normal to the principal direction. Then, with the concept of fixed crack approach, the shear transfer along the cracks must be addressed ${ }^{1 \text {. }}$.

The shear model of cracked concrete used in this study is based on the simplified contact density model ${ }^{13)}$ idealising the rough crack surface as a set of numerous contact units with various inclinations being distributed according to a contact density function. In each direction, a contact unit can transfer normal and shear stresses, which are formulated by a rigid-plastic model.

The infinite plastic deformation of contact units is in fact imaginary. Bujadham et al. ${ }^{14)}$ reported the softening of shear transfer mechanism as a function of shear displacement along cracks and introduced a degradation component for computing the contact stress. A simple shear softening concept adjusting the contact density shear transfer model for FE computations had been proposed by $\mathrm{An}$ et al. ${ }^{8)}$ multiplying the original integral formed shear transfer model with a decay function (Fig.10) as,

$$
\begin{array}{ll}
\tau=(\mathrm{G} \times \gamma) 1.0 & \text { if } \quad \gamma<\gamma_{u} \\
\tau=(\mathrm{G} \times \gamma)\left(\gamma_{u} / \gamma\right)^{\mathcal{C}} & \text { if } \quad \gamma \geq \gamma_{u}
\end{array}
$$

where, $\tau$ is mean shear stress, $\gamma$ is mean shear strain, $G$ is shear secant modulus according to the contact density model ${ }^{13)}, \gamma_{u}$ is the ultimate shear strain from which softening initialises ${ }^{8)}$ and $c$ is the softening parameter. Ultimate shear strain was adjusted to $400 \mu$ for plain concrete and $4000 \mu$ for reinforced concrete ${ }^{8)}$ and softening parameter is, for simplicity and lack of other information, assumed to be the same as used for tension softening/stiffening ${ }^{8)}$. It has been shown that the shear failure mechanism of RC beams and columns can be numerically 


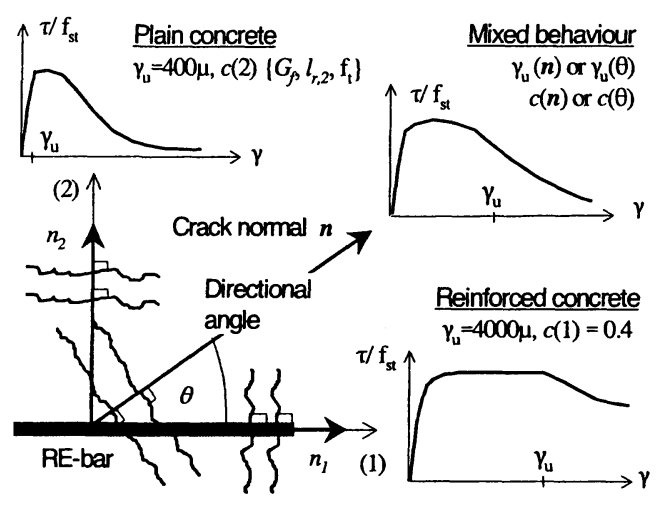

Fig.11 Anisotropy of shear transfer softening in 2D.

simulated for 2D problems $^{8)}$ if the distinct tension/shear softening as stated above is applied for reinforced and plain concrete zone, respectively.

In the formulation of the shear decay term in Eq.(10), the slope of the descending branch is altered according to Mode II fracture energy ${ }^{8)}$. In interaction with the softening parameter interpolation scheme for anisotropic tension fracture, the assumed softening branch of the shear transfer model is consistently defined for cracks being arbitrarily inclined with respect to reinforcing bars.

On the contrary, the onset of shear transfer decay denoted by $\gamma_{u}$ needs to be defined for the intermediate case between plain and reinforced concrete. It is proposed to vary the onset of shear transfer decay $\gamma_{u}$ (ultimate shear strain) depending on the crack inclination in space relative to reinforcing bars (Fig.11) in a similar manner as used for the tension softening parameter. In the orthogonal reinforcement bar system, $\gamma_{u}$ can be indicated for directions (1), (2) and (3) according to RC-zoning and for the arbitrary crack angle, $\gamma_{u}$ is interpolated as,

$$
\gamma_{u}(n)=\frac{n_{1}^{2} \gamma_{u}(1)+n_{2}^{2} \gamma_{u}(2)+n_{3}^{2} \gamma_{u}(3)}{n_{1}^{2}+n_{2}^{2}+n_{3}^{2}}
$$

where $n_{1}, n_{2}$ and $n_{3}$ are the components of the crack normal unit vector $\boldsymbol{n}$. An in-plane simplified situation is depicted in Fig.11 and Fig.12.

\section{(4) Anisotropic embedded reinforcement model}

A constitutive law for reinforcing bars in concrete has to be numerically modelled based both on properties of bare bars and on the effect of bond to concrete $^{1)}$. For reinforcing steel, compressive strains are usually significantly smaller than tensile strains, preventing reinforcement from excessive yielding in compression before spalling of concrete cover has occurred. At the tension side, however, highly

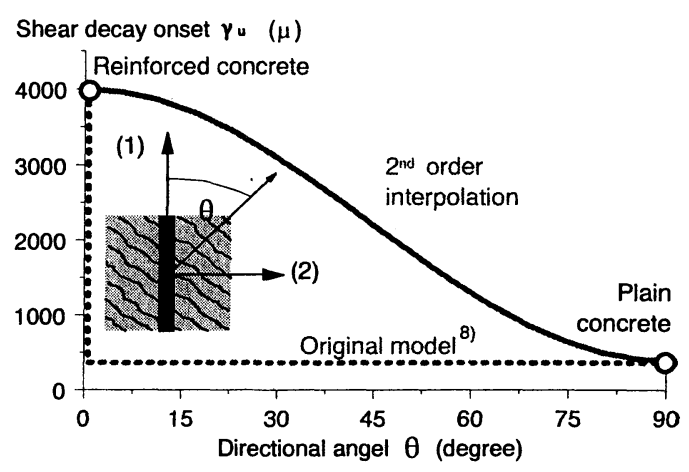

Fig.12 Interpolation of shear decay onset $\gamma_{u}$

localised plasticity at the vicinity of cracks has to be taken into account ${ }^{1}$. Consequently, modelling of reinforcement behaviour in compression and tension can be different ${ }^{15}$. For compression, complete strain compatibility can be assumed such that average and local behaviour of the reinforcing steel coincide and a simple bi-linear approximation of the bare bar behaviour suffices. For tensioned reinforcement, on the other hand, to include the effect of localised steel plasticity and bond within the concept of smeared modelling, an average stress - average strain formulation different from the local bare bar behaviour must be used ${ }^{1)}$. An essential input parameter for computing the average response of reinforcement is the effective reinforcement ratio defined as,

$$
\rho_{\text {eff }}=\mathrm{A}_{\mathrm{St}} / \mathrm{A}_{\mathrm{RC}}
$$

where, $A_{S t}$ is the area of steel considered to be effectively bonded to concrete in tension and $A_{R C}$ is the area of effective embedment (RC) zone of concrete where the reinforcing bars can influence on the crack widths (see Fig.5). With respect to reinforcement behaviour, $\rho_{\text {eff }}$ describes the concrete area relative to the bar size which is effective in restraining free elongation of the steel bar (RCzone). The larger the effective concrete area (or the smaller $\rho_{\text {eff }}$ ) is, the lower the average yield level would be. For direct tension, average yield stress of reinforcement embedded in concrete may be computed as ${ }^{16)}$,

$$
\bar{f}_{y}=f_{y}-\frac{f_{t}}{2 \rho_{\text {eff }}}
$$

After lower apparent yield stress is defined, a higher average hardening modulus often finalises the average stress - strain diagram for tension reinforcement embedded in concrete. For the 


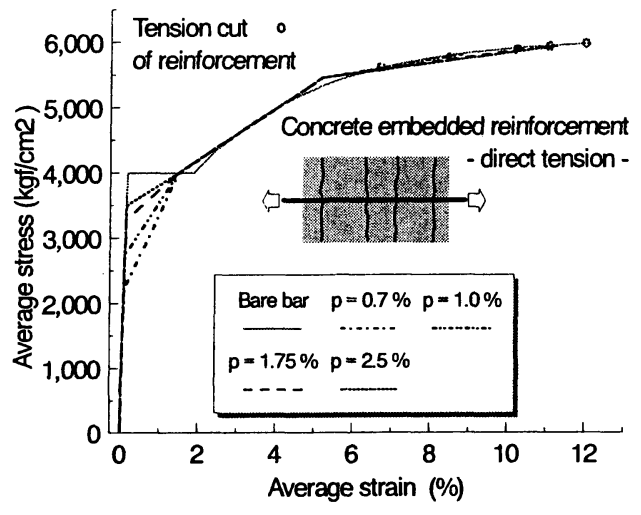

Fig.13 Quattro-linear average-based tension reinforcement model $^{16)}$.

analysis of most common reinforced concrete structures, such a bi-linear assumption ${ }^{1)}$ is sufficient since high tensile strains are not encountered due to early concrete compression failure.

However, in seismic analysis or for steel encased $\mathrm{RC}$-structures reinforcement, strain may reach very high tensile values leading eventually to a rupture of tension reinforcement. In such a case, bi-linear model would be quite a crude approximation, which may lead to less accurate results. Then, the versatile computational model for tension reinforcement proposed by Salem and Maekawa ${ }^{16)}$ is implemented as a quattro-linear approximation of the average stress - strain law up to the failure point (Fig. 13).

Experimental work and subsequent mathematical modelling on average response of steel bars embedded in concrete had been focusing on pure tension with cracks normal to the reinforcement ${ }^{5), 16)}$. In a more generic situation, however, cracks could not be expected to always form normal to a steel reinforcing bar. Then, consequently, formulations derived for direct tension must be revised for its applicability in 2D, 3D computations with arbitrary crack inclination relative to the reinforcing bars.

In Fig.14, a 2D simplified situation is depicted. As cracks form normal to the reinforcing bar, average steel behaviour can be computed according to models derived from direct tension, e.g. Eq.(13), where the effective reinforcement ratio is obtained from RC-zone. If, however, cracks are parallel to the reinforcement, considerable amount of concrete volume, which otherwise could restrain the free elongation of the steel bar, may be cut off. In this situation bare bar behaviour is assumed for simplicity, although some small concrete volume may still be attached to steel. For any other situation with discretionally inclined cracks with respect to reinforcement, steel response must be in-between bare bar and direct tension behaviour as simply illustrated in Fig.14.
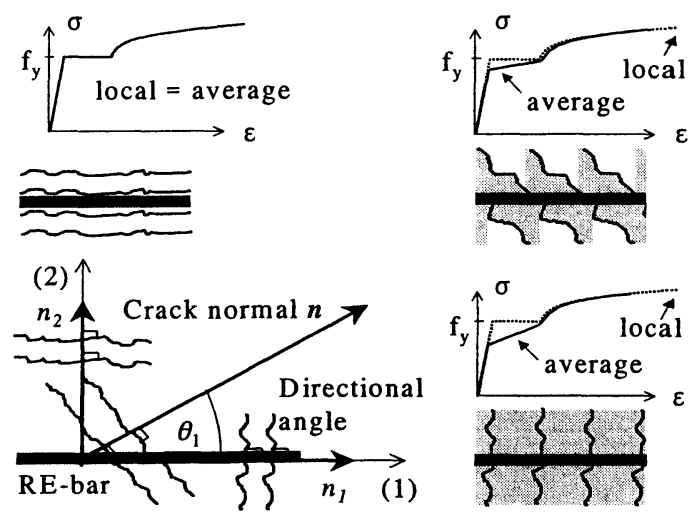

Fig.14 Anisotropic yield strength of tension reinforcement embedded in concrete.

Table 1 Material parameters

\begin{tabular}{|c|c|c|c|c|c|c|}
\cline { 2 - 7 } \multicolumn{1}{c|}{} & $\begin{array}{c}\mathrm{f}_{\mathrm{c}}{ }^{\prime} \\
\mathrm{kg} / \mathrm{cm}^{2}\end{array}$ & $\begin{array}{c}\mathrm{f}_{\mathrm{t}} \\
\mathrm{kg} / \mathrm{cm}^{2}\end{array}$ & $\begin{array}{c}\mathrm{f}_{\mathrm{y}} \\
\mathrm{kg} / \mathrm{cm}^{2}\end{array}$ & $\begin{array}{c}\rho_{\text {eff }} \\
\%\end{array}$ & $\begin{array}{c}\overline{\mathbf{f}}_{\mathrm{y}} \\
\mathrm{kg} / \mathrm{cm}^{2}\end{array}$ & $\begin{array}{c}\text { Lc } \\
\mathrm{cm}\end{array}$ \\
\hline VQ1 & 195 & 11.7 & 4560 & 0.55 & 3511 & 10.0 \\
\hline VQ4 & 175 & 10.9 & 4560 & 1.10 & 4058 & 8.5 \\
\hline
\end{tabular}
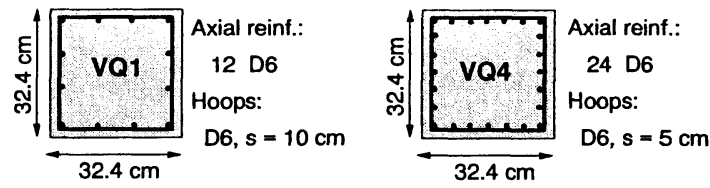

Fig.15 Torsion beams, Leonhardt and Schelling ${ }^{17)}$.

To consider the varying mean yield strength of steel bars embedded in concrete with respect to the crack direction, the $2^{\text {nd }}$ order interpolation between bare bar $\left(\mathrm{f}_{\mathrm{y}}\right)$ and embedded bar direct tension $\left(\overline{\mathrm{f}}_{\mathrm{y}}\right)$ behaviour is introduced (see Fig.16). In each respective reinforcing direction $(i)$, the effective mean yield strength $\overline{\mathrm{f}}_{\mathrm{y}, \text { eff }}$ may be computed with respect to crack direction as,

$$
\overline{\mathrm{f}}_{\mathrm{y}, \text { eff }}(i)=\mathrm{f}_{\mathrm{y}}(i)-\left[\mathrm{f}_{\mathrm{y}}(i)-\overline{\mathrm{f}}_{\mathrm{y}}(i)\right] n_{i}^{2}
$$

where $n_{i}$ is the component of the crack normal unit vector $\boldsymbol{n}$ in bar direction $(i), \overline{\mathrm{f}}_{\mathbf{y}}(i)$ is the mean yield strength of reinforcing bar $(i)$ if normal cracks are assumed. Introducing the directional angle $\theta_{i}$ of the crack normal $\boldsymbol{n}$ relative to the reinforcing bar $(i)$ (Fig.14) we have $n_{i}=\cos \theta_{i}$ and hence can also write,

$$
\left.\overline{\mathbf{f}}_{\mathbf{y}, \text { eff }}(i)=\mathbf{f}_{\mathbf{y}}(i)-\mathbf{f}_{\mathbf{y}}(i)-\overline{\mathbf{f}}_{\mathbf{y}}(i)\right] \cos ^{2} \theta_{i}
$$



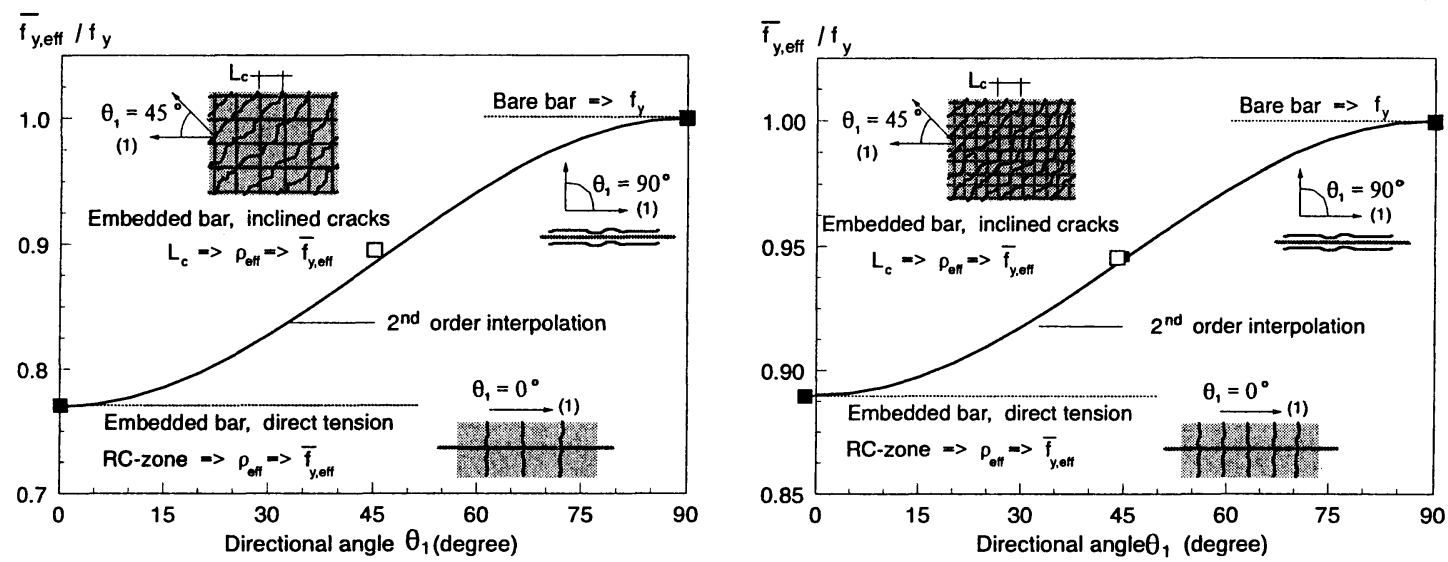

Fig.16 Comparison of $2^{\text {nd }}$ order interpolation of $\overline{\mathbf{f}}_{\mathrm{y}, \text { eff }}$ with analytical results obtained from observed crack spacing: VQ1 \&VQ4 ${ }^{17)}$.

To materialise the above introduced interpolation scheme of effective mean yield level, two reinforced concrete beams subjected to pure torsion are chosen $^{17)}$ (Fig.15, Table 1). In the case of torsion, cracks would form under an inclination of about $45^{\circ}$ to the reinforcing bars ensuring a situation different from uni-axial tension. In Fig.16, the $2^{\text {nd }}$ order interpolation for specimens VQ1 and VQ4 between direct embedded bar in tension and bare bar behaviour is shown. In the test report, the crack pattern is given and the average crack spacing can be estimated (Table 1). Average crack spacing can also be computed according to the local bond based semi-empirical model of Salem ${ }^{18)}$ as,

$$
\begin{gathered}
\mathrm{L}_{\mathrm{c}}=\mathrm{L}_{c 0} \mathrm{~K}_{\rho} \mathrm{K}_{\mathrm{y}} \mathrm{K}_{\mathrm{t}} \mathrm{K}_{\mathrm{c}} \mathrm{K}_{\mathrm{d}} \\
\mathrm{K}_{\rho}=\left(\rho_{\text {eff }} / 0.01\right)^{-0.5}
\end{gathered}
$$

where, $\mathrm{L}_{\mathrm{c} 0}=50 \mathrm{~cm}$. Coefficients describing the influence of effective reinforcement ratio, steel yield strength, concrete tensile and compression strength as well as bar diameter on average crack spacing. Since average crack spacing is given, Eq.(16) can be re-arranged as,

$$
\rho_{\text {eff }}=0.01\left(\frac{\mathrm{L}_{c 0} \mathrm{~K}_{\mathrm{y}} \mathrm{K}_{\mathrm{t}} \mathrm{K}_{\mathrm{c}} \mathrm{K}_{\mathrm{d}}}{\mathrm{L}_{\mathrm{c}}}\right)^{2}
$$

and the effective reinforcement ratio is inversely computed according to the observed average crack spacing. Finally, apparent mean yield level is obtained from Eq.(13) and plotted over the observed directional angle of $\theta_{1} \approx 45^{\circ}$ as shown in Fig.16. Fair agreement with the proposed $2^{\text {nd }}$ order interpolation of mean yield strength, as assumed in Eq.(14), is observed, implicitly verifying the proposed crack direction dependent interpolation of mean yield strength. As an explicit verification, effectiveness of Eq.(14) in finite element computations will be demonstrated in the next section.

\section{RC-MEMBERS SUBJECTED TO TORSION}

Among the basic load bearing mechanisms of structures, namely axial loading, flexure, shear and torsion, only the latter is a truly three-dimensional problem. All other basic mechanisms are problems of two or even only one dimensions. For reinforced concrete structures, the case of pure torsion is rather exceptional, commonly torsion acts in combination with other mechanisms of shear and/or bending. However, the case of pure torsion as a pre-requisite for the general solution of complex loading has been the target of many researchers ${ }^{17), 19), 20)}$. Since torsion of structural concrete has been experimentally well investigated, it is a good target of analysis for improving and verifying the 3Danalysis concept. Then, after passing the "torsion test" numerical tool coded as COM3 is anticipated to be improved a step further in the direction of predicting reinforced concrete response under arbitrary load conditions. This shall be the true and final goal of development of full 3D reinforced concrete model.

\section{(1) Mesh size sensitivity}

To verify the general analytical frame of concrete and mesh objectivity in inclined cracking situations, unaffected from reinforcement, RC-zoning or tension stiffening formulations, plain concrete beams subjected to pure torsion are analysed. Two 
A2 $(25.4 \times 38.1 \mathrm{~cm})$

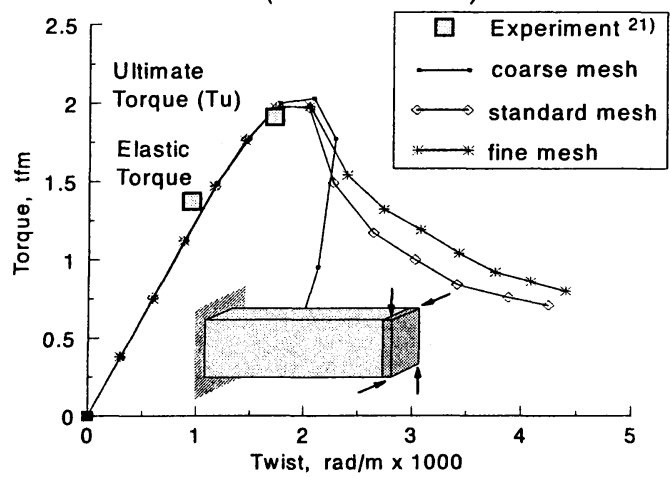

A3 $(25.4 \times 25.4 \mathrm{~cm})$

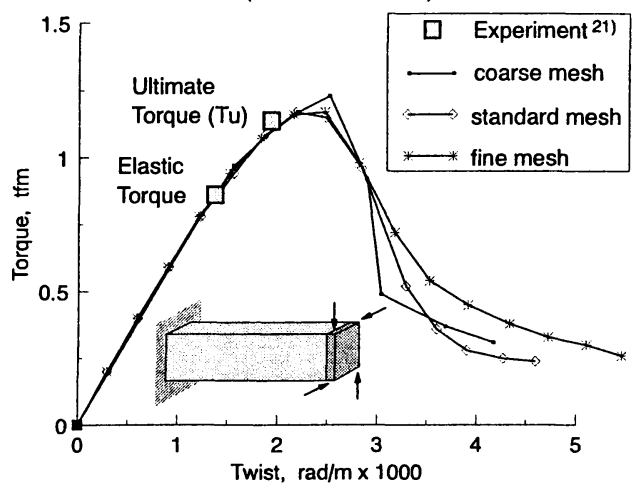

Fig.17 Plain concrete rectangular (A2) and square (A3) section torsion beams: mesh size sensitivity study.

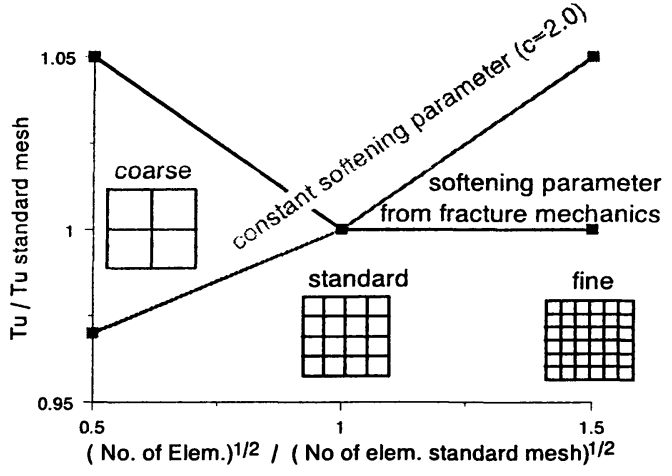

Fig.18 Ultimate torque for mesh size dependent and independent tension softening (specimen A3).

concrete beams with square and rectangular crosssections, respectively, are chosen ${ }^{21)}$. As an analysis input parameter, only mean cylinder compressive strength of the test series ${ }^{21)}$ is taken. Tensile strength, Young's modulus and tensile fracture energy are estimated from the cylinder strength by JCI and CEB-FIP model code (1990) empirical formulas, respectively. Three different meshes are investigated. One is coarse mesh representing the lower bound, a standard mesh commonly employed in analysis and fine mesh requiring large computational power.

The results for the rectangular section (specimen A2) as shown in Fig.17 indicate even for the coarse mesh a nearly acceptable prediction of cracking and ultimate torque (15\% too high value). Only descending branch gives unlike results. Because, computational failure is localised and located outside the twist reference length, and unloading response of material is much included in the reference zone specified in experiment due to quite large size of elements. Standard and fine meshes almost coincide until peak and only slightly deviate in the descending part. For the square section (specimen A3), computed results give a similar tendency. Considering the spread of material parameters within the test series, the results are understood to be acceptable.

In Fig.18, the normalised ultimate torque for specimen A3 is plotted for the three different meshes. For standard and finer mesh, the same ultimate torque is obtained while the coarse mesh results in a slightly higher value since discretisation is too rough to grasp the actual strain gradient. At the same time, specimen A3 was also analysed using mesh independent tension softening, described by a constant softening parameter $c \quad(c=2.0)$ in Eq.(3) ${ }^{1)}$. Now, as the mesh gets more refined ultimate torque increases as expected.

However, it is interesting to notice that for the standard mesh fracture mechanics approach ${ }^{8)}$ and experimentally obtained constant softening parameter ${ }^{1)}$ specified yield the similar good results. Nevertheless, using fracture mechanics approach the required objectivity with respect to mesh refinement seems to be given if too coarse mesh is avoided.

\section{(2) Influence of RC-zoning on torsion analysis}

Efficiency of 2D sub-space based 3D-smeared crack model ${ }^{4)}$ and mesh independency of results have been shown by analysing plain concrete beams subjected to torsional loading. Here, the concept of 3D RC-zoning and anisotropy of softening as well as mean yield strength (Chapter 3) are to be scrutinised by analysing RC-members with full three-dimensional load bearing mechanisms, namely reinforced concrete torsion beams.

Mitchell and Collins ${ }^{20)}$ had tested several prestressed concrete beams under pure torsion load including only one conventionally reinforced beam (P6), which has been chosen as the first target of 


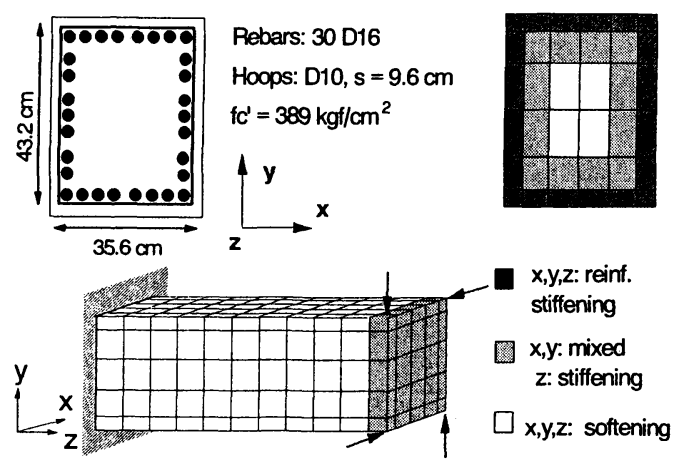

Fig.19 Properties and RC-zoning of P6 torsion beam ${ }^{20)}$.

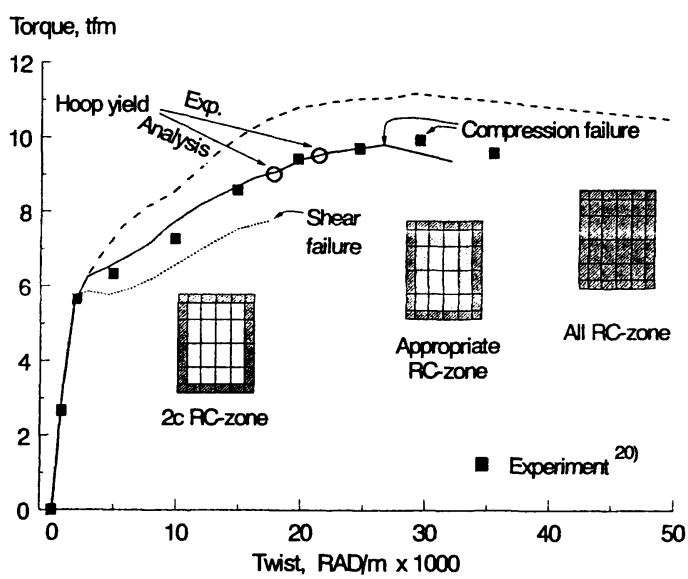

Fig.20 Influence of RC-zoning on post-cracking torsion response (Specimen P6).

analysis. Dimensions, material properties and finite element discretisation and load application are given in Fig.19. Results of the computed torque-twist relationships are compared with the experimental data $^{20)}$ in Fig.20. Provided that RC-zone is only allocated as twice the concrete cover (2c), much energy is rapidly released just after initial cracking. Consequently, post-cracking stiffness and ultimate capacity are considerably reduced in comparison with experimental data.

On the other hand, if whole concrete volume would be assumed as reinforced concrete, the postcracking stiffness and ultimate torque capacity are by far too high. RC-volume determined according to the $3 \mathrm{D}$ zoning technique in chapter 3 (the proposed standard in this paper) leads to reasonable torquetwist relationship. From the presented example, it may become clear that neither the whole concrete volume nor a very small RC-skin is appropriate for torsion analysis.

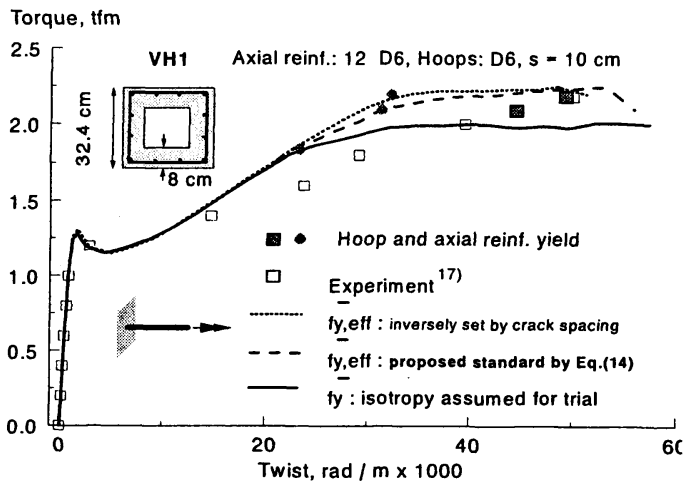

Torque, $\mathrm{tfm}$

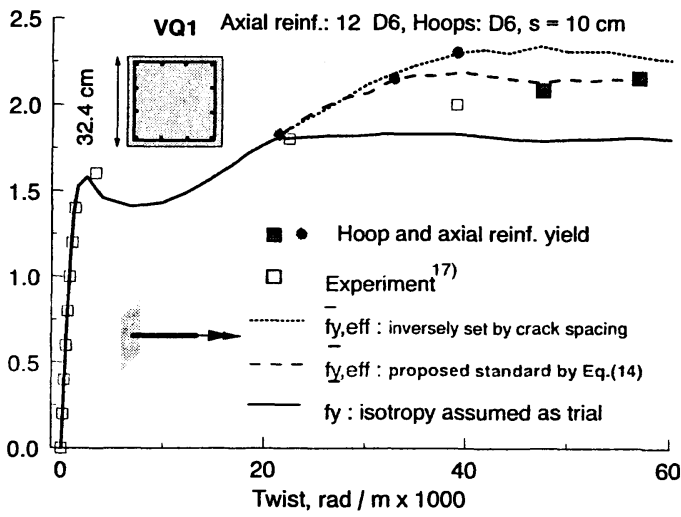

Fig.21 Influence of anisotropic yield strength.

\section{(3) Influence of anisotropic yield strength}

In Fig.21, hollow and solid sectional torsion members designated by VH1 and VQ1 are shown ${ }^{17)}$. Reinforcement quantity is low such that yielding is anticipated as the primary failure mechanism. According to RC-zoning and Eq.(12), an effective reinforcement ratio of about $0.4 \%$ is obtained. With this value, the specimens are firstly analysed using average yield strength computed according to Eq.(13), independent of crack inclination. As depicted in Fig.21, premature yielding of reinforcement occurs in this case. Following, $\rho_{\text {eff }}$ is directly computed from observed crack spacing using Eq.(17) and corresponding mean yield strength is again obtained by Eq.(13). The computed torque - twist relationship fairly matches with experimental data ${ }^{17}$. In particular, yield moment and ultimate torque agree nicely (Fig.21). Finally, mean yield strength interpolation is employed as the proposed standard here for predicting structural response without any factor identification from experimentally observed crack patterns. Similar as for the first analysis, $\rho_{\text {eff }}$ is obtained from RCzoning and corresponding mean yield strength for 


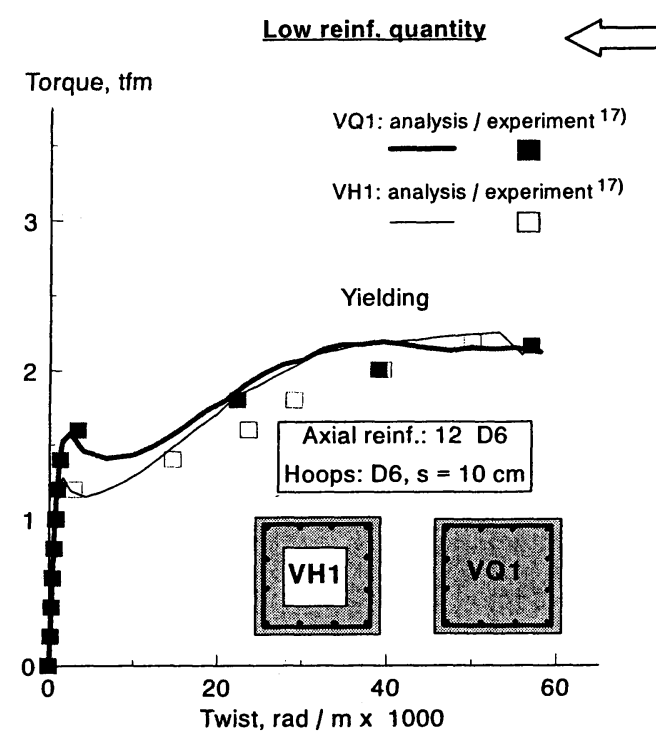

High reinf. quantity

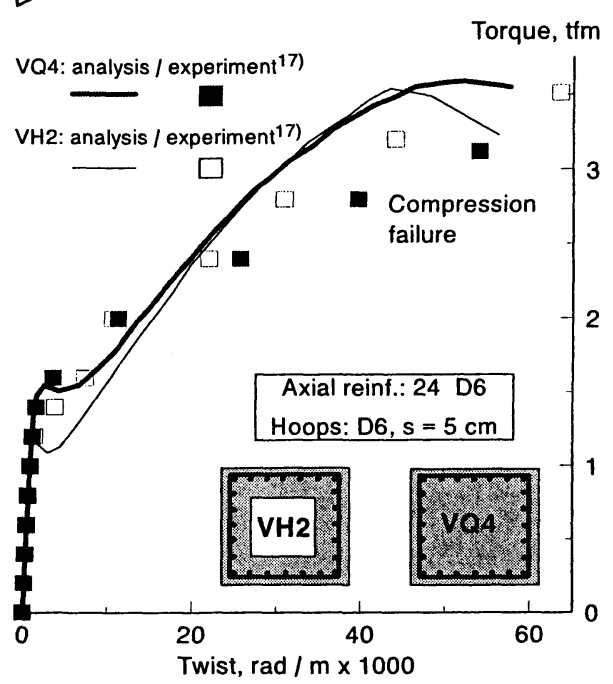

Fig.23 Influence of anisotropic yield strength.

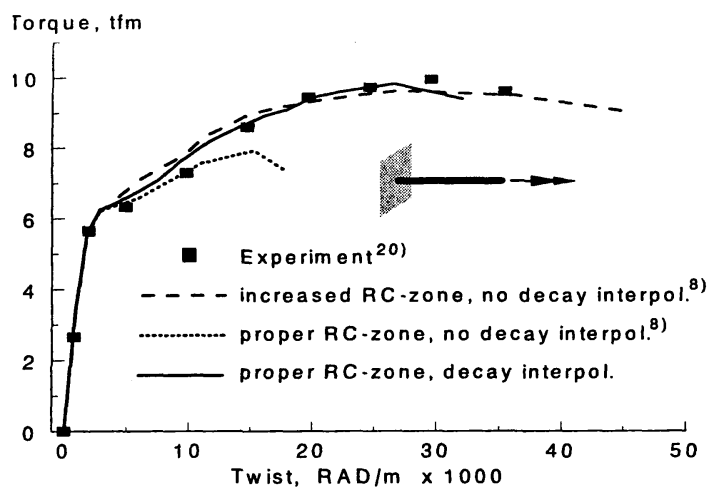

Fig.22 Influence of shear decay onset and RC-zone: $\mathrm{P}^{20)}$.

direct tension is computed from Eq.(13). Here, mean yield strength is computed and reduced owing to the crack inclination relative to the reinforcing bars as described by Eq.(14). The obtained results agree with those obtained from direct utilisation of crack spacing as well as experimental data ${ }^{19)}$ as shown in Fig.21 explicitly supporting the validity of the interpolation approach.

Good agreement of numerically predicted and experimentally observed reinforcement yielding can also be found for specimen $\mathrm{P6}^{20)}$ (see Fig.20) further sustaining the proposed method. Thus, it may be concluded that the average yield strength of reinforcement does indeed depend on crack inclination relative to steel bars as proposed in this paper. Anisotropy of tension stiffening and softening associated with steel orientation is crucial.
(4) Effect of anisotropic shear transfer decay

Shear transfer decay, as introduced in chapter 3, may influence shear capacity or even failure mode as had been demonstrated for shear beams ${ }^{8)}$. But, as pointed out previously, also the shear strain level from which the decay of shear stresses transferred is considered may play an important role. In order to evaluate the effect of the proposed shear decay onset interpolation between that for cracks normal and parallel to reinforcement, all other model parameters as previously introduced were kept constant in analysis. Computational results for specimen $\mathrm{P}^{19}{ }^{19}$ are shown in Fig.22.

As no decay onset interpolations would be considered, meaning that shear decay starts at 4000 $\mu$ for cracks normal to cracks in RC-zone and at 400 $\mu$ for all other crack inclinations with respect to reinforcement, a premature failure is found in analysis. If RC-zone would be increased beyond the size determined by 3D RC-zoning method or we use the proposed standard in this paper, computational results come closely to experimental data. Then, the authors accept the RC-zoning method, tentatively in view of engineering application. But, it is necessary to discuss more on the possible combination of further refined RC zoning in terms of macro bond property and shear decay in future.

\section{(5) Solid and hollow torsion members}

For reinforced concrete members, it is well known that there is a little variance in torsional response between thick-walled hollow members and solid ones which otherwise have similiar properties $^{20), 22)}$. To further solidify the analysis 


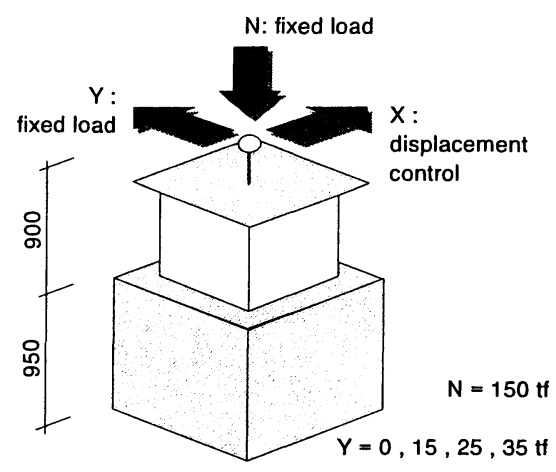

Fig.24 Setup of short RC column loaded in bi-axial shear ${ }^{23)}$.

scheme of torsional RC-members, four beams with solid (VQ-series) or hollow (VH-series) square cross section were selected ${ }^{17}$. For all beams, axial and lateral reinforcement ratios coincide. Specimens $\mathrm{VH} 2$ and VQ4 are distinguished from specimen VH1 and VQ1 by a 50\% higher amount of reinforcement (Fig.23). All previously scrutinised methods of 3D RC-zoning, anisotropic tension softening and interpolations, shear transfer decay and anisotropic mean yield strength are considered in analysis. Results of numerical simulation are compared with experimental data ${ }^{17)}$ in Fig.23. For low and high reinforcement quantity, ultimate torsional capacity of solid and hollow sections is, as anticipated, very close together. For specimens with low reinforcement content (VH1 and VQ1), numerical failure was caused by yielding of reinforcement. Resulting large deformations finally caused concrete compression failure. Highly reinforced specimens (VH2 and VQ4), on the other hand, failed in diagonal concrete compression before reinforcement yielding. Similar failure mechanisms are also reported for tested beams ${ }^{17}$.

\section{RC COLUMNS SUBJECTED TO BI-AXIAL SHEAR}

The study of plain and reinforced concrete torsion members is useful for general verification of 3Dsmeared crack model with unstable and stable propagation of 3D inclined cracks, respectively. However, it should be noted that even for inherently 3D torsion loading, principal stress direction does not turn in 3D but rotates just in a restricted 2Dstress field. Then, the capability of simulating multidirectional cracks in complete 3D extent has not been fully exploited and verified by the analysis conducted so far. With this background in mind, short RC columns under varying multi-directional
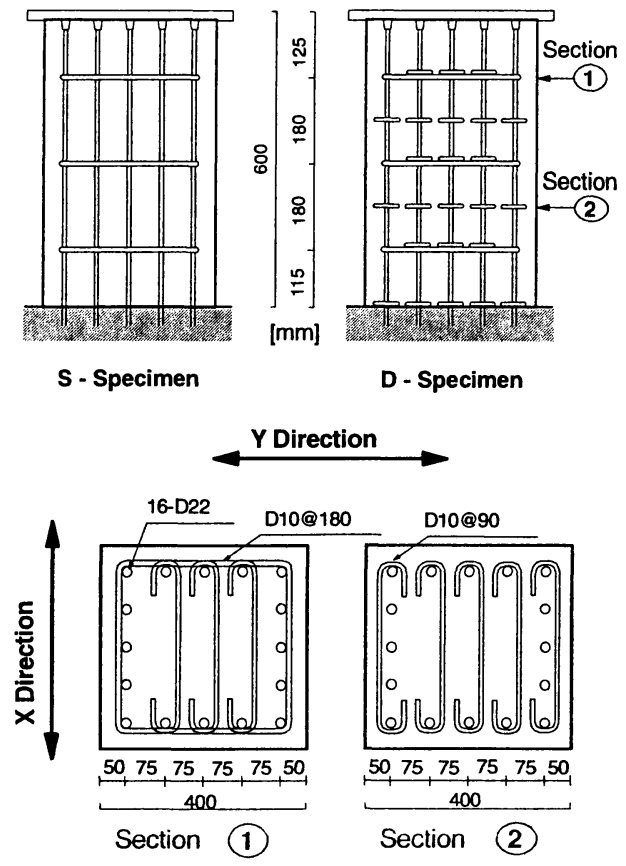

Fig.25 Bi-axial shear reinforcement layout ${ }^{23)}$.

shear forces were selected to scrutinise the proposed schemes of 2D break down of strain field and 3D recomposition of 2D partial stresses as well as 3D anisotropy of tension fracture and its interpolation as described in chapter 3.

Fig.24 illustrates a set-up of the short RC columns ${ }^{23)}$ which will be used for verification of the full 3D non-linear analysis frame. A constant axial load (150tf) and fixed horizontal load in Y-direction $(0,15,25,35$ tf for different specimens) were applied. After setting these forces, varying enforced displacement in X-direction normal to the already applied shear is monotonically applied until failure (Fig.24). Under this load application scheme, the complexity of stress fields which accompanies triaxially varying inclined cracks and corresponding principal stress directions is recognised. It means that spatial development of stress induced cracks is irregular unlike reinforced concrete of 2D in shear.

Specimens with two different reinforcement arrangements were tested ${ }^{23}$. For S-series specimens, only three stirrups were placed while specimens of $\mathrm{D}$-series have additional hoops in X-direction (Fig.25). The reduced effectiveness of the additional hoops in D-series due to non-uniform stress distribution was taken into account by subtracting twice the minimum anchorage length (CEB-FIP MC-90) from the actual length and considering only this reduced length in the computation for premature bond stress development close to concrete cover. 

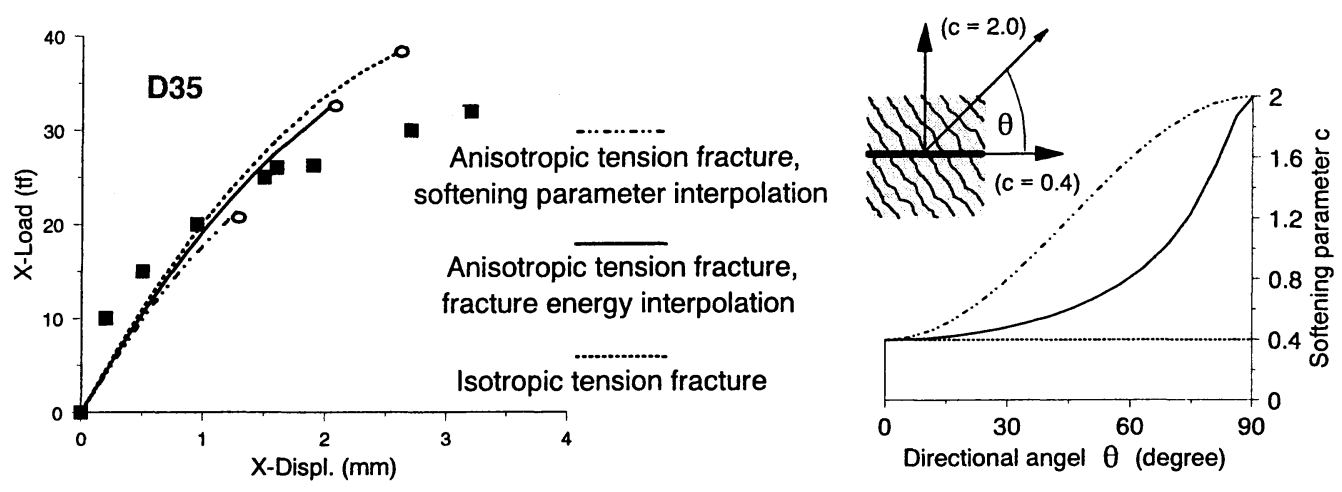

Fig.26 Effect of isotropic or anisotropic tension fracture and interpolations.

(1) Influence of anisotropic tension fracture and interpolation

A concept of spatial variable tension softening/stiffening associated with crack direction relative to steel reinforcement was discussed in chapter 3. It was concluded that cracked concrete should obey tension stiffening normal to reinforcing bars and localised tension softening parallel to it. This was named anisotropic tension softening. The concept seems to be self-explaining since it is physically evident that the parallel crack must soften and the perpendicular stiffen (Fig.26) and hence element-wise isotropic tension stiffening can not be versatile within the concept of spatial average based modelling.

Nevertheless, utilising specimen D35 from Dseries, as above described, isotropic and anisotropic tension softening concepts are numerically compared. In all trial analyses, the horizontally applied constant force in Y-direction is no longer sustained in computation, no matter how stable horizontal displacement is settled. Then, no plastic flow in X-direction is shown in Fig.26. It becomes visible that isotropic tension stiffening may overestimate the actual load capacity. Only if all cracks would form normal to reinforcement, isotropic idealisation can be supposed to yield equivalent numerical results.

Anisotropic tension softening shall be regarded as the standard from hereafter. However, it remains to scrutinise the influence of the interpolation method for arbitrally inclined cracks. It was argued, that a direct interpolation of softening parameter $c$, which governs the slope of the descending branch of the tension stress-strain diagram as described in Eq.(3), would lead to a severe underestimation of the anticipated tension stiffening effect for cracks nonperpendicular to reinforcement, since it is nonproportional to the consumed fracture energy (Fig.9). Then, a concept was introduced solving the softening parameter for the variable crack inclination from the interpolated normalised fracture energy $G_{f}^{*}$ as illustrated in Fig.9.

Specimen D35 was chosen again for comparison of numerical results. It features the strongest directional shift between initial and ultimate shear plane combined with uni-directional additional shear reinforcement making an accurate definition of tension softening/stiffening in crucial space. In Fig.26 numerical results for both above-mentioned interpolation strategies are plotted. As expected, mere interpolation of softening parameter results in a load capacity much below the experimentally obtained value ${ }^{23)}$. Interpolation of normalised fracture energy and implicitly obtained corresponding softening factor on the other hand leads to fair agreement of analytical and experimental bi-axial shear capacity which is understood as a verification of the proposed scheme of anisotropic tension fracture and fracture energy based interpolations.

\section{(2) Bi-axial shear force interaction diagram}

In order to further confirm that the proposed model may predict the evolution of the spatially inclined variable shear plane under non-proportional loading, all specimen of the above described experimental series ${ }^{23)}$ are analysed. In Fig.27 the experimental and the computed X-load - Xdisplacement curves for all $S$ - and $D$-series specimens are plotted. As the level of pre-imposed $\mathrm{Y}$-load increases, the initial stiffness in X-direction decreases in computation due to pre-accumulated damage. The influence of the additional hoops in Xdirection, improving stiffness and ultimate shear capacity in that direction is qualitatively and correctly reflected in analysis.

Fig.28 shows the shear force interaction diagrams. Failure mode in computation was judged by checking the instability process of iterative computation. The progressive cracking in finite elements and accompanying energy release under 

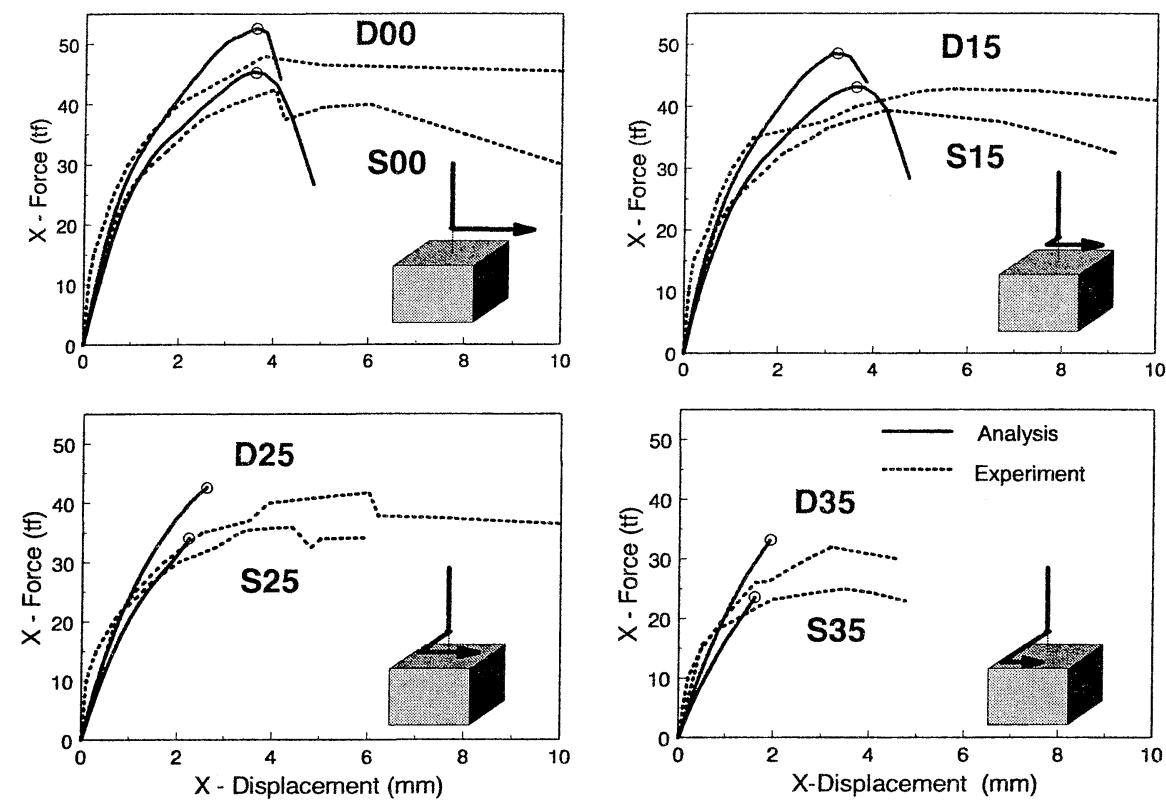

Fig.27 Bi-axial shear: load-displacement diagram (X-direcion).

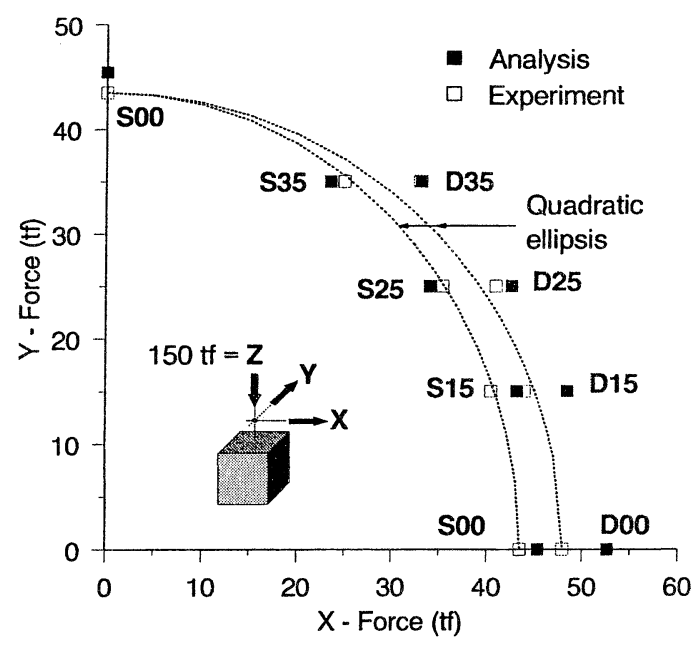

Fig.28 Bi-axial shear: $\mathrm{X}-\mathrm{Y}$ force interaction diagram.

enforced displacement are the criterion of shear failure. In case were no post peak response could be obtained, numerical instability point was defined as computed prediction of ultimate capacity and the instability was checked not to be affected by load steps. Analysis fairly grasps the reduction of shear capacity in one direction as the shear load in the other direction increases. For D-series specimen with additional X-reinforcement, shear capacity in $\mathrm{X}$-direction is improved. Here, the effect of the hoops seems to be overestimated in the simulation, although only reduced hoop length was considered in computation as described above. Consequently, the predicted capacity in $\mathrm{X}$-direction is a little higher in the case of lower shear force in $\mathrm{Y}$ direction.

As mentioned before (Fig.24), load application was mixed force- and displacement-controlled. For force-controlled loading, generally no post-peak response is obtained. Then, observing computed load-displacement diagrams as shown in Fig.27, it seems to be reasonable that for specimens with larger force-controlled pre-imposed Y-load (S25, S35, D25, D35), which is kept constant, no postpeek response could be computed. Since the constant Y-load largely contributes to the totally applied force, no post-peak solution exists for numerical simulation with perfect boundary conditions as described above (Fig.24).

However, during experiments ${ }^{23)}$ after the ultimate load had been reached, the pre-imposed Y-load could not be kept constant but dropped swiftly. Only under such imperfect conditions, different from the numerical simulations, a post-peak response exists. On the other hand, for specimens with no or only small force-controlled contribution to the total load (S00, S15, D00, D15), descending branch could be computed with sustainable orthogonal shear force in Y-direction, though it is much steeper than observed in experiments ${ }^{23)}$.

Up to the peak of load displacement diagrams, full 3D constitutive models works well with reasonable accuracy for engineering purpose. The load interaction for multi-directional action can be fairly predicted in accordance with the experimental results. Nevertheless, still in the descending portions 


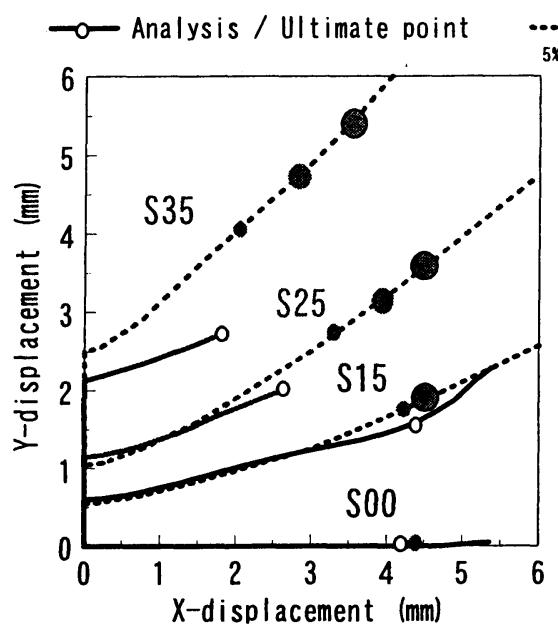

a) S-series
Experiment / UItimate point

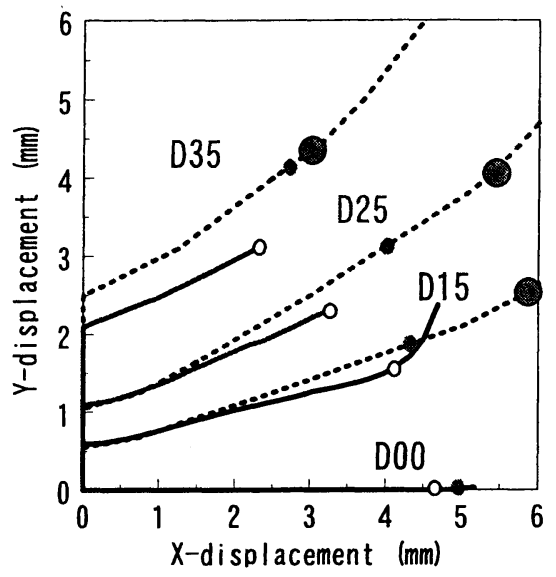

b) D-Series

Fig.29 Bi-axial displacement path: member + joint response in analysis.

of the diagrams, computation is not successful. In experiments, a remarkable remaining post-peak strength and ductility were observed ${ }^{23)}$. In fact, arclength method of iteration with some restraint can not be adopted due to the horizontal load being kept nearly constant. Here, strain localisation in compression remains unsolved in finite element analysis. The post-peak compression softening can be regarded as one of the essential points for a sound prediction of the descending part of the load deflection diagram. Furthermore, it should be noted that the present formulation does not explicitly consider any dowel action of the reinforcing bars, which might become important as an element of resistance in localised shear cracks close to or postpeak.

\section{(3) Bi-directional displacement path}

When we evaluate results of numerical simulation it is not sufficient only to compare the bi-axial shear force diagram with experimental data. Additionally, the displacement path of the bi-directional loaded short columns shall be studied. In Fig.29, the bidirectional displacement history is plotted. Displacement at ultimate shear capacity is marked by ${ }^{\circ}$ for the numerical value and by ${ }^{-}$for the experimental data ${ }^{23)}$. Any further displacement is those of the post-peak descending branch. For comparing analytical results with experimental data the effect of pullout of reinforcing bars from footing needs to be considered ${ }^{1), 24)}$. For experimental data ${ }^{23)}$ give only the total response, not distinguishing member and joint-based displacements separately, joint behaviour needs to be taken into account in analysis").

First, the analytical displacement path of member basis is already shown in Fig.27. Following, jointbased displacement is determined in a separate analysis employing RC discrete crack model ${ }^{25,26)}$ for the column-footing joint together with rigid brick elements for the columns. The joint element models the pullout of reinforcing steel out of concrete and the mechanism of stress transfer due to the interaction of aggregate along the crack surface ${ }^{25)}$. Dowel action of reinforcing steel is neglected.

Fig.29 gives the superposition of computed joint and member displacements in comparison with experimental data ${ }^{23)}$. The general trend of the experimental data can be predicted by this kind of analysis, especially the flow direction of column heads under multi-directional actions. Nevertheless, still some quantitative discrepancy must be admitted. One reason could be that the shear transfer model ${ }^{13)}$ used in the joint element ${ }^{25)}$ is that developed for 2D problems. Applied to 3D analysis in $\mathrm{X}$ - and $\mathrm{Y}$ direction, shear transfer is not interrelated but assumed independent. This could partly explain the larger gap between experimental and analytical displacement-path for specimen with strong bidirectional loading (S25, S35, D25, D35).

And we should pay attention to the timedependent flow of displacement when the force is kept constant close to the capacity in experiment. This was experienced in the experiment and the analysis with time independent $\mathrm{RC}$ modelling does not cover the rapid inelastic creep flow. 

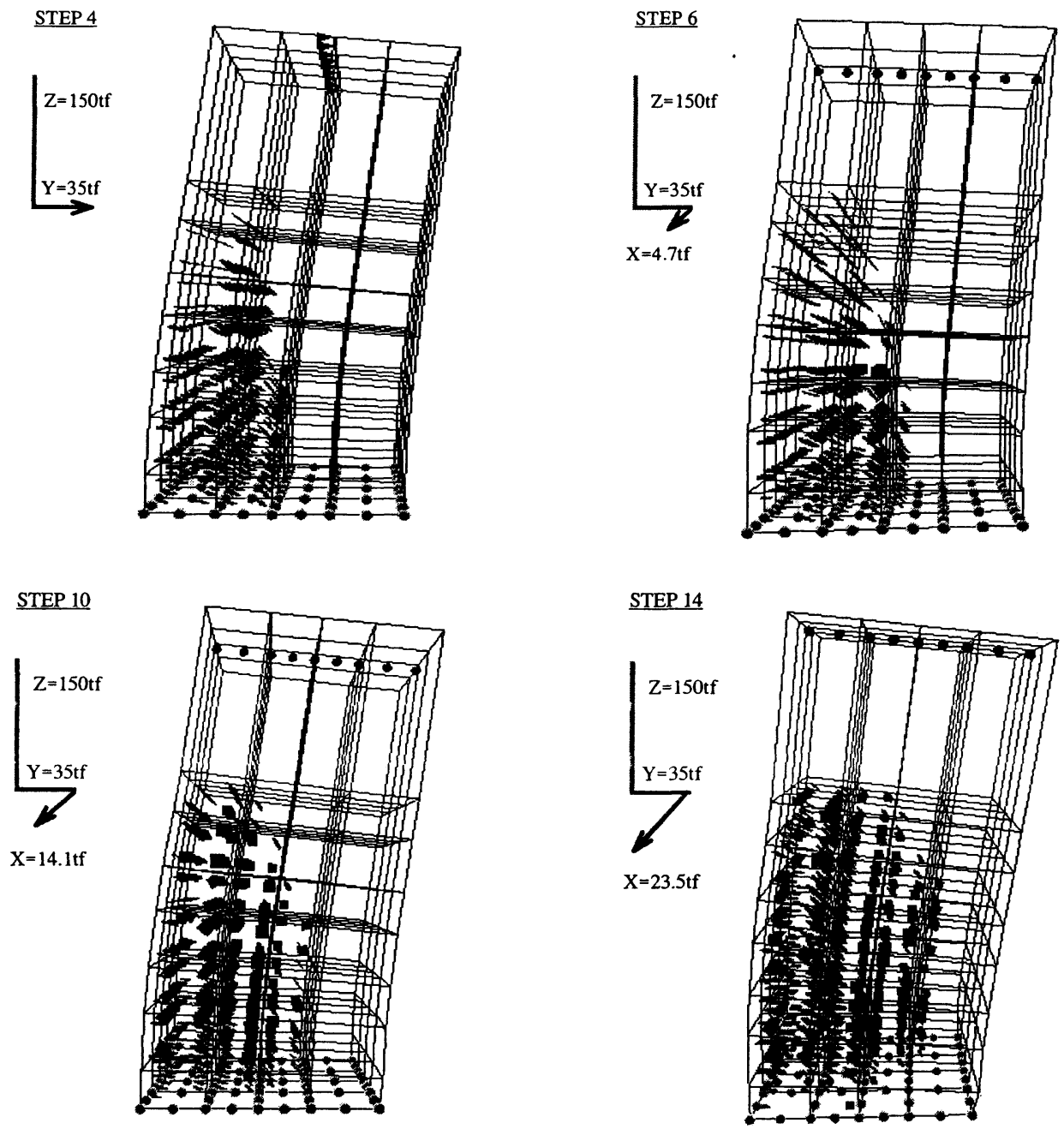

Fig.30 Evolution of 3D inclined variable cracks under multi-directional non-proportional loading: S35.

(4) Visualisation of varying crack inclination

Full 3D analysis of concrete structures results in an overflow of output-data giving displacement and reaction force for each nodal point as well as complete average stress and strain vectors and internal parameters of plasticity, damage and cracking at each Gaussian integration point. Then, in employing quadratic interpolation function and $2^{\text {nd }}$ order integration, we have information of 20 nodes and eight integration points for each finite brick element. Handling such abundance of information in a thoughtful way could provide the researcher with so many valuable insight of numerical and presumably true behaviour of complex concrete structures.

Post-processing for two-dimensional computer codes is well advanced and many nice graphical tools are available making the daily life of concrete researchers and engineers easier. But, analysis tools of full 3D are lacking and naturally, post-processing codes of 3D are even less developed. Nevertheless, especially for the understanding of varying threedimensionally inclined crack planes as observed for multi-directionally loaded reinforced concrete such a visualisation must be crucial. The advent of multimedia now gives new opportunities for a quick advance. Using Virtual Reality Modelling Language, Takahashi and Maekawa ${ }^{27)}$ provide a new opportunity of virtually "looking inside" cracked concrete. Node and integration point data are read and transformed to a VRML input format. Primary care is taken of the spatial direction of the predominant crack at each integration point ${ }^{27)}$. As non-proportional loading changes its direction, new cracks are introduced and indicated as governing over the existing crack, hence visualised crack 
direction is changed. Deformation data are also collected. In such a way a graphical tool has been constructed making it possible to observe the complex cracking behaviour of multi-directionally loaded reinforced concrete ${ }^{27)}$.

As an example, step by step development of predominant three-dimensionally variably inclined cracks for specimen S35 is given here. Specimen S35 had been selected because it guaranties the maximum directional variation of initial shear cracking plane and intersecting final shear failure plane. A relatively large $\mathrm{Y}$-force of $35 \mathrm{tf}$ being applied first followed by displacement controlled loading up to failure in the perpendicular $\mathrm{X}$ direction as seen in Fig.30. Crack plane at each Gaussian integration point is indicated by a small plate with spatial orientation decided according to the observed predominant crack. Deformation of the specimen is shown as well.

In step 1, axial load of 150 tf is applied and naturally no cracks can be found for the load is compressive and far from the ultimate. In step 2 to 4 , fixed horizontal $Y$-force is applied in $11.67 \mathrm{tf}$ increments resulting in a total of 35 tf. After full Yforce is applied in step 4 (Fig.30), typical inclined shear cracks have developed. As Y-direction is kept clamped and displacement controlled load is applied in the perpendicular X-direction from step 5 on, initially induced cracks remain predominant until step 6 (Fig.30) and only few cracks change their direction by creating new non-orthogonal cracking. In step 10 (Fig.30), already most of the plates representing governing crack plane of an integration point, turned from the initial Y-plane inclination toward spatial inclination. This tendency is reinforced in the following steps resulting in the final shear failure plane being completely altered from the originally induced shear crack plane. Step 14 (Fig.30) finally has been identified as the step just before unstable crack propagation occurs and hence, has been designated as the ultimate load level. Here, the fully three-dimensionally inclined shear plane can be clearly identified.

\section{CONCLUSIONS}

Full three-dimensional constitutive laws of reinforced concrete were proposed for RC solids with multi-directional cracks, and their applicability under monotonic forces was examined. Complete 3D-space expanded EPF model ${ }^{2), 3)}$ was proposed for un-cracked concrete. For 3D cracked concrete, a 2D breakdown and 3D re-composition scheme of smeared crack analysis ${ }^{4)}$ was scrutinised. The mesh independence of the formulation was demonstrated by analysing plain concrete torsion beam with different mesh discretisations. Anisotropy of tension fracture was recognised as bond mechanism controlled stable and dispersed crack propagation for cracks normal to reinforcement must be distinguished from the unstable and localised behaviour of cracks parallel to reinforcement.

To account for anisotropy of tension fracture in the 3D domain, a method of three-dimensional RCzoning and fracture energy based softening parameter interpolation was presented. In a similar way, it was concluded that average based response of tension reinforcement depends on the crack inclination relative to reinforcement. Where cracks parallel to reinforcement may result in a behaviour close to the unconstrained bare bar normal cracks cause the localised plasticity in the vicinity of those cracks. Crack inclination dependent interpolation of average yield strength was found an effective measure to address this phenomenon.

The proposed framework of 3D nonlinear analysis was successfully applied to the numerical response prediction of hollow and solid torsion members with low and high reinforcement quantities. For short RC columns under multi-axial load, the 3D inclined variable shear plane and its associated shear failure were simulated.

Further development toward a truly versatile computational tool for examining structural performance of reinforced concrete sustaining complex loading patterns seems to be a challenging topic of today's research. The performance-based design scheme of future structural codes requires engineers to check the specified limit states. Here, especially, structures have to be checked for seismic or accidental resistance in reasonable consistency with material and structural mechanics. The physically consistent solutions of the compression localisation and buckling of reinforcement embedded in concrete are regarded as the crucial points of further research for obtaining the reliable post-peak response.

\section{REFERENCES}

1) Okamura, H. and Maekawa, K.: Nonlinear analysis and constitutive models of reinforced concrete, GihodoShuppan Co., Tokyo, 1991.

2) Maekawa, K., Takemura, J., Irawan, P. and Irie, M.: Triaxial elasto-plastic and continuum fracture model for concrete," Concrete Library, JSCE, No. 22, pp.131-161, 1993.

3) Hauke, B. and Maekawa, K.: Three-dimensional reinforced concrete model with multi-directional cracking, Computational modelling of concrete structures, de Borst et al. eds., Balkema, Rotterdam and Brookfield, pp. 93-102, 1998.

4) Maekawa, K., Irawan, P. and Okamura, H.: Path-dependent three-dimensional constitutive laws of reinforced concrete 
- formulation and experimental verifications, Structural Engineering and Mechanics, Vol. 5. No. 6, pp. 743-743, 1997.

5) Fukuura, N. and Maekawa, K.: Multi-directional crack model for in-plane reinforced concrete under reversed cyclic actions - 4 way fixed crack formulation and verification, Computational modelling of concrete structures, de Borst et al. eds., Balkema, Rotterdam and Brookfield, pp. 143-152, 1998.

6) Cervenka, V. and Margoldova, J.: Tension stiffening effect in smeared crack model, ASCE EMD Specialty Conference, May 21-23, University of Colorado, Boulder, USA, 1995.

7) Shima, H., Chou, L. and Okamura, H.: Micro and macro models for bond behaviour in reinforced concrete, Journal of the Faculty of Engineering, The University of Tokyo (B), Vol. IIIXIX, No. 2, pp. 133-194, 1987.

8) An, X., Maekawa, K. and Okamura, H.: Numerical simulation of size effect in shear strength of RC beams, $J$. of Materials, Concrete Structures and Pavements, JSCE, Vol. 35, pp. 297-316, 1997.

9) Gupta, S. and Tanabe, T.: Unified concrete plasticity model in three dimensional analysis of reinforced concrete members, Proc. of JCI, pp. 561-566, 1997.

10) Barzegar, F. and Maddipudi, S.: Three-dimensional modelling of concrete structures, J. of Struct. Eng, Vol. 123, pp. 1339-1356, 1997.

11) Salem, H.M., Hauke, B. and Maekawa, K.: Fracture of concrete cover - its effect on tension stiffening and modeling, Proc. of JSCE annual convention, 1998.

12) Bazant, Z.P. and Oh, B.: Crack band theory for fracture of concrete, RILEM Mat. Struct., Vol. 16, pp.155-177, 1983.

13) Li, B., Maekawa, K. and Okamura, H.: Contact density model for stress transfer across cracks in concrete, Journal of the Faculty of Engineering, The University of Tokyo (B), Vol. XL, No. 1, pp. 9-52, 1989.

14) Bujadham, B. and Maekawa, K.: The universal model for stress transfer across cracks in concrete, Proc. of JSCE, No. 451/V-17, pp. 277-287, 1992.

15) General Task Group 22 of the CEB: $R C$ elements under cyclic loading, CEB state of the art report, Thomas Telford, London, 1996.
16) Salem, H.M. and Maekawa, K.: A versatile computational model for reinforced concrete in tension, Proc. of annual meeting JSCE Kanto, 1998.

17) Leonhardt, F. and Schelling, G.: Torsionsversuche an Stahlbetonbalken, DAfStB, Ernst \& Sohn, Berlin, 1974.

18) Salem, H.M.: Enhanced tension stiffening model and application to nonlinear dynamic analysis of reinforced concrete, Ph.D thesis, The University of Tokyo, 1998.

19) Hsu, T.T.C.: Torsion of structural concrete - a summary on pure torsion, Torsion of structural concrete, SP-18, ACI, Detroit, pp. 165-178, 1968.

20) Mitchell, D. and Collins, M.P.: Influence of prestressing on torsional response of concrete beams, PCI Journal, Vol. 23, No. 3, pp. 55-72, 1978

21) Hsu, T.T.C.: Torsion of structural concrete - plain concrete rectangular sections, Torsion of structural concrete, SP-18, ACI, Detroit, pp. 203-238, 1968.

22) Hsu, T.T.C.: Torsion of structural concrete - behaviour of reinforced concrete rectangular members, Torsion of structural concrete, SP-18, ACI, Detroit, pp. 261-306, 1968.

23) Yoshimura, M.: Failure envelope of RC columns in twoway shear, Summaries of Technical Papers of Annual Meeting, AIJ, pp. 199-200, 1996 (in Japanese).

24) Mishima, T. and Maekawa, K.: Development of RC discrete crack model under reversed cyclic loads and verification of its applicable range, Concrete Library, JSCE, No. 20, pp115-142, 1992.

25) Maekawa, K. and Qureshi, J.: Behavior of embedded bars in concrete under combined axial pullout and transverse displacement, Concrete Library, JSCE, No. 28, 1992.

26) Hauke, B.: Three-dimensional modelling and analysis of reinforced concrete and concrete composites, $\mathrm{PhD}$ thesis, The University of Tokyo, 1998.

27) Takahashi, T. and Maekawa, K.: Visualisation of three dimensional RC crack analysis using immersive multiscreen display, Proc.of JCI, Vol 20, No. 1, pp. 149-154, 1998 (in Japanese).

(Received December 3, 1998)

\section{多方向ひび割れを有する鉄筋コンクリートの 3 次元モデル化}

$$
\text { ベルンハルト ハウケ・前川宏一 }
$$

本論文は,ひび割れを有する鉄筋コンクリート要素の 3 次元構成モデルを提案するものである. 一方向ひ び割れにおけるひび割れ以後の応力開放挙動を,多方向に交差する任意の傾斜を有するひび割れに対して一 般化を図った. 3 次元 RCゾーニングの考え方と連関付け,引張破壊の異方性と鉄筋の平均降伏強度につい て議論した．提案された要素モテルに対して,ねじりを受ける RC 部材のせん断破壊と,多方向加力を受け る短柱のせん断破壊解析を通じて検証を行った. 